\title{
Sequences Flanking the Gephyrin-Binding Site of GlyR $\beta$ Tune Receptor Stabilization at Synapses
}

\author{
Nora Grünewald, ${ }^{1}$ (D)Audric Jan, ${ }^{2}$ Charlotte Salvatico, ${ }^{2}$ Vanessa Kress, ${ }^{1}$ (D) Marianne Renner, ${ }^{3}$ (D)Antoine \\ Triller, ${ }^{2}{ }^{\circledR}$ Christian G. Specht, ${ }^{2}$ and ${ }^{\circledR}$ Guenter Schwarz ${ }^{1,4,5}$
}

\section{DOI:http://dx.doi.org/10.1523/ENEURO.0042-17.2018}

${ }^{1}$ Department of Chemistry, Institute of Biochemistry, University of Cologne, Cologne 50674, Germany, ${ }^{2}$ École Normale Supérieure, Centre National de la Recherche Scientifique, Institut National de la Santé et de la Recherche Médicale, Institute of Biology (IBENS), Paris Sciences et Lettres Research University, Paris 75005, France, ${ }^{3}$ Institut du Fer à Moulin (IFM), Université Pierre et Marie Curie, Paris 75005, France, ${ }^{4}$ Center for Molecular Medicine Cologne (CMMC), University of Cologne, Cologne, Germany, and ${ }^{5}$ Cologne Excellence Cluster on Cellular Stress Responses in Aging-Associated Diseases (CECAD), University of Cologne, Cologne, Germany

\begin{abstract}
The efficacy of synaptic transmission is determined by the number of neurotransmitter receptors at synapses. Their recruitment depends upon the availability of postsynaptic scaffolding molecules that interact with specific binding sequences of the receptor. At inhibitory synapses, gephyrin is the major scaffold protein that mediates the accumulation of heteromeric glycine receptors (GlyRs) via the cytoplasmic loop in the $\beta$-subunit ( $\beta$-loop). This binding involves high- and low-affinity interactions, but the molecular mechanism of this bimodal binding and its implication in GlyR stabilization at synapses remain unknown. We have approached this question using a combination of quantitative biochemical tools and high-density single molecule tracking in cultured rat spinal cord neurons. The high-affinity binding site could be identified and was shown to rely on the formation of a $3_{10}$-helix $\mathrm{C}$-terminal to the $\beta$-loop core gephyrin-binding motif. This site plays a structural role in shaping the core motif and represents the major contributor to the synaptic confinement of GlyRs by gephyrin. The N-terminal flanking sequence promotes lower affinity interactions by occupying newly identified binding sites on gephyrin. Despite its low affinity, this binding site plays a modulatory role in tuning the mobility of the receptor. Together, the GlyR $\beta$-loop sequences flanking the core-binding site differentially regulate the affinity of the receptor for gephyrin and its trapping at synapses. Our experimental approach thus bridges the gap between thermodynamic aspects of receptor-scaffold interactions and functional receptor stabilization at synapses in living cells.
\end{abstract}

Key words: bimodal binding; binding site; gephyrin; glycine receptor; receptor clustering

\section{Significance Statement}

The number of receptors at a synapse defines the strength of signal transmission and is directly dependent on the binding of the receptors to scaffold proteins beneath the synaptic membrane. In this study, we discovered the molecular basis for a dual-affinity interaction between glycine receptors (GlyRs) and gephyrin scaffolds. We identified GlyR sequences that are specifically required for high- and low-affinity binding. Using single-molecule tracking in cultured neurons both sites were shown to act as elements regulating the diffusion and trapping of GlyRs as a result of the altered receptor-scaffold binding. The novelty of our approach lies in the unique combination of biochemical data of purified proteins with single molecule diffusion analysis. It exemplifies that binding properties can be extracted by analyzing the diffusion behavior of molecules in living cells. 


\section{Introduction}

The amount of neurotransmitter receptors at synapses determines the strength of synaptic transmission. While the receptors diffuse laterally in the neuronal plasma membrane due to Brownian motion, their accumulation at synapses is a consequence of the transient binding to postsynaptic scaffold proteins (Dahan et al., 2003; Choquet and Triller, 2013). The molecular processes underlying the receptor-scaffold interaction can thus shed light on the diffusion-trapping mechanism at synapses and its implication in the regulation of synaptic transmission (Choquet and Triller, 2003; Petrini and Barberis, 2014).

Gephyrin is the major scaffolding molecule at inhibitory synapses, providing a platform for the immobilization of glycine receptors (GlyRs) and GABA type A receptors $\left(\mathrm{GABA}_{\mathrm{A}} \mathrm{Rs}\right.$; Kirsch et al., 1993; Tyagarajan and Fritschy, 2014). Gephyrin is a multifunctional protein that catalyzes a metabolic reaction in all tissues (Fritschy et al., 2008) in addition to its receptor clustering function in neurons. Both GlyRs and $\mathrm{GABA}_{\mathrm{A}}$ Rs belong to the pentameric family of ligand-gated ion channels (pLGICs), in which each subunit consists of an enlarged $\mathrm{N}$-terminal ligand binding domain followed by four transmembrane domains (TMs; Corringer et al., 2012). The third and fourth TMs are connected via large intracellular loops (ILS) that bind to the C-terminal E-domain of gephyrin with subunit-specific affinities (Sola et al., 2004; Tretter et al., 2008, 2011; Maric et al., 2011, 2014a; Specht et al., 2011; Kowalczyk et al., 2013). In the case of the GlyR and gephyrin binding is mediated by the $\beta$-subunit (Meyer et al., 1995; Patrizio et al., 2017). Consequently, gephyrin depletion completely abolishes the synaptic clustering of GlyRs (Levi et al., 2004; Zacchi et al., 2008), which in turn leads to severe encephalopathy due to the failure in inhibitory neurotransmission (Dejanovic et al., 2015).

Given the importance of GlyR-gephyrin binding for inhibitory signal transmission in the spinal cord and the brainstem, the molecular interaction between the receptor

Received February 1, 2017; accepted January 15, 2018; First published February 9, 2018.

The authors declare no competing financial interests.

Author contributions: N.G., A.T., C.G.S., and G.S. designed research; N.G., A.J., C.S., V.K., and C.G.S. performed research; N.G., A.J., C.S., V.K., M.R., C.G.S., and G.S. analyzed data; N.G., C.S., A.T., C.G.S., and G.S. wrote the paper.

This work was supported by the German Science Foundation Grant SFB 635 TPA11 (to G.S.), the Center for Molecular Medicine Cologne (G.S.), the Agence Nationale de la Recherche Synaptune Grant ANR-12-BSV4-0019-01 (to A.T.), the European Research Council (ERC) Plastinhib (A.T.), and the program Investissements d'Avenir Grants ANR-10-LABX-54 MEMO LIFE and ANR-11IDEX-0001-02 PSL Research University (to A.T.). A.J. is supported by the ERC Grant CellO (to Jean-Louis Viovy, Institut Curie, Paris).

Acknowledgements: We thank the University of Cologne CECAD proteomics facility (Tobias Lamkemeyer) for peptide mass fingerprinting, Xiaojuan Yang, Monika Laurin, Simona Jansen, and Joana Stegemann for technical help.

Correspondence should be addressed to either of the following: Guenter Schwarz at the above address, E-mail: gschwarz@uni-koeln.de; or Christian G. Specht at the above address, E-mail: specht@ens.fr.

DOI:http://dx.doi.org/10.1523/ENEURO.0042-17.2018

Copyright @ 2018 Grünewald et al.

This is an open-access article distributed under the terms of the Creative Commons Attribution 4.0 International license, which permits unrestricted use, distribution and reproduction in any medium provided that the original work is properly attributed. and scaffold proteins has been subject to detailed biochemical characterization. These studies disclosed a twosite or bimodal binding mechanism based on two different binding affinities (Schrader et al., 2004; Sola et al., 2004; Herweg and Schwarz, 2012). However, the molecular determinants of this bimodal binding and their specific effects on receptor trapping at synapses have not been identified. In this study, we have applied a biochemical approach to identify the molecular determinants that underlie the two-site binding mechanism between the GlyR $\beta$-loop and gephyrin. Using single-particle tracking in living rat spinal cord neurons, we could show that the highand low-affinity interactions regulate receptor diffusion, demonstrating that bimodal binding is a central property coordinating GlyR trapping at inhibitory synapses. The combination of biochemical data and diffusion parameters revealed a close correspondence between the two approaches, highlighting the potential of diffusion measurements to access thermodynamic parameters of interacting molecules in living cells (as proposed by Masson et al., 2014).

\section{Materials and Methods}

\section{Escherichia coli expression constructs}

The $\beta$-loop $(\beta \mathrm{L})$ sequence encompassing amino acid residues $378-426$ of the GlyR $\beta$ subunit fused to intein (pTYB2) was used as the wild-type construct (Schrader et al., 2004). Truncation variants of the $\beta \mathrm{L}$ were generated via PCR to generate fragments spanning 378-413 and $394-426$, corresponding to $\beta \mathrm{L}-\mathrm{LO}$ and $\beta \mathrm{L}-\mathrm{HI}$, respectively. The core $\beta L$ peptide (394-413) was purchased from Pepnome (USA) with a purity of $96.72 \%$. The residues Asp407 and Phe 408 of the $\beta \mathrm{L}$ were exchanged to Pro and Gly via site-directed mutagenesis of the wild-type sequence. Chemical crosslinking and ITC interaction studies were performed with recombinant full-length gephyrin rC4 or GephE, cloned into pQE80 vector (Belaidi and Schwarz, 2013). The $\beta \mathrm{L}$ variants, full-length gephyrin and GephE were expressed in the $E$. coli strain BL21 and purified according to the protocol described below (Schrader et al., 2004; Dejanovic et al., 2015).

\section{Purification of recombinant proteins from $E$. coli}

Intein-fused $\beta \mathrm{L}$ variants were affinity purified in lysis buffer containing $300 \mathrm{mM} \mathrm{NaCl}, 50 \mathrm{mM}$ Tris/ $\mathrm{HCl} \mathrm{pH}$ 8.0, 1 mM EDTA and protease inhibitors (Complete, Roche) via the IMPACT system (New England Biolabs) according to Schrader et al. (2004). Cleavage of the $\beta \mathrm{L}$ variants was induced by the addition of cleavage buffer $(50 \mathrm{mM} \mathrm{NaCl}$, $100 \mathrm{mM}$ Tris/HCl pH 7.5, 1 mM EDTA) containing 50 mM DTT as thiol and incubated for $24 \mathrm{~h}$ at room temperature. Cleaved $\beta$ Ls were separated from larger proteins and enriched using semi-permeable cellulose membrane containing devices with decreasing cutoff (10, $3 \mathrm{kDa}$; Millipore). Buffer was exchanged to ITC measurement buffer (10 mM Tris/ $\mathrm{HCl} \mathrm{pH} 8.0,250 \mathrm{mM} \mathrm{NaCl}$, and $1 \mathrm{mM}$ $\beta$-mercaptoethanol) via dialysis over night at $4^{\circ} \mathrm{C}$. After expression in E. coli, full-length gephyrin and GephE were purified by Ni-NTA chromatography in $300 \mathrm{mM} \mathrm{NaCl}$ and $30 \mathrm{mM}$ Tris/ $\mathrm{HCl} \mathrm{pH} 8.0$, containing protease inhibitors and 
10 or $25 \mathrm{mM}$ imidazole, respectively. For gephyrin, additional washing steps were performed with an increasing imidazole gradient (45-60 mM imidazole) and a final concentration of $250 \mathrm{mM}$ imidazole for elution. Gephyrin was additionally purified by size exclusion chromatography (Superdex 16/600 prep grade) in ITC measurement buffer. GephE was further enriched via anion exchange chromatography (SourceQ15, buffer A: $50 \mathrm{mM}$ Tris/HCl pH 8.0; buffer $\mathrm{B}: 50 \mathrm{mM}$ Tris/ $\mathrm{HCl} \mathrm{pH} \mathrm{8.0,} \mathrm{and} 1 \mathrm{M} \mathrm{NaCl}$ ), followed by buffer exchange (ITC measurement buffer). All buffers for gephyrin and GephE purification were additionally supplied with $5 \mathrm{mM} \beta$-mercaptoethanol.

\section{Lentivirus expression constructs and virus production}

Single molecule imaging was conducted in cultured spinal cord neurons using membrane constructs in which the $\beta$-loop of GlyR $\beta$ (N334-A455) was fused at its $C$ terminus to a single TM of syntaxin and an extracellular Dendra2 fluorophore (derived from $\beta \mathrm{L}^{\mathrm{wt}}$-TMD-pHluorin; Specht et al., 2011). Deletions and point mutations were introduced into the $\beta$-loop by site-directed mutagenesis (variants TMD- $\beta$ LHI: $\Delta$ V378-L393; TMD- $\beta$ L- $\Delta$ Core: $\Delta$ D397-L410; TMD- $\beta$ LD407P/F408G; gephyrin binding-deficient TMD- $\beta$ L-geph: F398A/I400A). The coding sequences of the $\beta$ L-TMDDendra2 variants were transferred into the $\mathrm{pFUGW}$ replicon (Lois et al., 2002) for lentivirus production (FU- $\beta$ L-TMDDendra2 constructs).

To study the behavior of full-length GlyR complexes, we generated a lentivirus construct driving the expression of mEos4b-tagged GlyR $\beta$ (construct FU-mEos4b-hGlyR $\beta$ bis, derived from FU-SP-myc-Dendra2-GlyR $\beta$; Patrizio et al., 2017). The mEos $4 \mathrm{~b}$ sequence (Addgene) with a C-terminal SGGTGKEKS spacer was inserted after the signal peptide (SP) sequence (between residues S26 and S27 taking into account the SP) of full-length human GlyR $\beta$ (UniProt ID P48167-1) and transferred into the pFUGW vector. The following deletions and point mutations were introduced into the wild-type $\beta$-loop: variants GlyR $\beta$-HI ( $\Delta$ V378-L393); GlyR $\beta$-LO ( $\Delta$ D414-L426); GlyR $\beta$ D407P/F408G; GlyR $\beta$-geph- (F398A/I400A).

Lentivirions were produced in HEK293 cells that were co-transfected with the replicon, pMD2.G and pCMVdR8.74 plasmids (Addgene) using Lipofectamine 2000 (Invitrogen) and cultured at $32^{\circ} \mathrm{C}$ and $5 \% \mathrm{CO}_{2}$ in neurobasal medium containing glutamax and $2 \% \mathrm{~B}-27$. The medium was changed after $24 \mathrm{~h}$ and harvested at $\sim 50 \mathrm{~h}$ after transfection, passed through a filter with a pore size of $0.45 \mu \mathrm{m}$ and stored at $-80^{\circ} \mathrm{C}$.

\section{Chemical crosslinking}

The $\beta L$ and gephyrin interacting sites were analyzed by chemical crosslinking using 1-(3-dimethylaminopropyl)3-ethylcarboiimide $\mathrm{HCl}$ (EDC; ThermoScientific) as described previously with minor modifications (Havarushka et al., 2014). Experiments were performed as suggested in the data sheet (ThermoScientific) and the reaction stopped with $50 \mathrm{mM}$ Tris/ $\mathrm{HCl}, \mathrm{pH}$ 8.0. Samples of crosslinked proteins were separated via $6 \%$ SDS-PAGE, followed by Coomassie staining. The bands at corresponding sizes were extracted for tryptic digestion and subsequent pep- tide mass fingerprinting (LC-MS/MS; Tobias Lamkemeyer) in the Proteomics Facility of the Cologne Cluster of Excellence in Cellular Stress Response in Agingassociated Diseases (CECAD) and performed as described in Havarushka et al. (2014).

\section{Isothermal titration calorimetry (ITC)}

ITC measurements were performed using a VP-ITC system. Interaction analysis took place at $25^{\circ} \mathrm{C}$ in ITC buffer $(10 \mathrm{mM}$ Tris/ $\mathrm{HCl} \mathrm{pH} 8.0$ or $7.4,250 \mathrm{mM} \mathrm{NaCl}$, and $1 \mathrm{mM} \beta$-mercaptoethanol) with cell concentrations of 20 $28.6 \mu \mathrm{M}$ gephyrin and $187-335 \mu \mathrm{M}$ purified $\beta \mathrm{L}$ as ligand. Each experiment was repeated using proteins from independent preparations. Reference power was set to 5 $\mu \mathrm{cal} / \mathrm{s}$. The ligand was injected after an initial delay of 120 $\mathrm{s}$ with a stirring speed of $310 \mathrm{rpm}$ using volumes of 3-5 $\mu \mathrm{l} / 3-5 \mathrm{~s}$ for each of 50 injections with $240-\mathrm{s}$ spacing. Raw data were analyzed using Origin 7 software.

\section{Circular dichroism (CD) spectroscopy}

The secondary structure of $\beta \mathrm{L}-\mathrm{wt}$ and $\beta \mathrm{L}-\mathrm{D} 407 \mathrm{P} / \mathrm{F} 408 \mathrm{G}$ peptides was analyzed and compared by CD spectroscopy in the far-UV spectrum (190-260 nm) according to the description in Havarushka et al., (2014). The buffer was exchanged to $100 \mathrm{mM} \mathrm{NaCl}, 50 \mathrm{mM}$ sodiumphosphate buffer $\mathrm{pH}$ 7.0. CD spectra were recorded from $190-260 \mathrm{~nm}$ in a $0.1 \mathrm{~cm}$ light path quartz cuvette at $20^{\circ} \mathrm{C}$ with a scanning speed of $10 \mathrm{~nm} / \mathrm{min}$ using a J-715 CD spectropolarimeter (Jasco). Each spectrum was recorded five times and averaged before each measurement. For background subtraction, a buffer baseline was additionally recorded and subtracted from the sample spectrum. In respect to the molecular weight $\left[\mathrm{M}_{\mathrm{r}}(\mathrm{Da})\right]$, the number of amino acids $(\mathrm{n})$, the protein concentration $[\mathrm{mg} / \mathrm{ml}]$ and the path length of the cuvette [l $(\mathrm{cm})]$, the measured ellipticity $\theta$ in millidegrees was converted to mean residue ellipticity $[\theta]$ in $\operatorname{deg} * \mathrm{~cm}^{2} * \mathrm{dmol}^{-1}$ using the following formula: $[\theta]=$ $\theta * \mathrm{M}_{\mathrm{r}} / 10 *(\mathrm{n}-1) * \mathrm{c} * \mathrm{I}$. The mean residue ellipticity $[\theta]$ was plotted against the respective wavelength.

\section{Cell culture}

Spinal cord dissociated neuron cultures were prepared from Sprague Dawley rats of either sex at embryonic day 14 (Specht et al., 2013), in accordance with the guidelines of the French Ministry of Agriculture and the Direction Départementale des services vétérinaires de Paris (École Normale Supérieure, animalerie des rongeurs, license B 75-05-20). Neurons were plated on glass coverslips at a density of $60,000 / \mathrm{cm}^{2}$ in neurobasal medium containing glutamax, $2 \% \mathrm{~B}-27,5 \mathrm{U} / \mathrm{ml}$ penicillin and $5 \mathrm{mg} / \mathrm{ml}$ streptomycin (Invitrogen) and grown at $36^{\circ} \mathrm{C}$ and $5 \% \mathrm{CO}_{2}$. Neurons were generally infected with lentivirus on the first day in vitro (DIV) and used for experiments on DIV 10-14.

\section{Live imaging}

Spinal cord neurons expressing $\beta$ L-TMD-Dendra2 variants were imaged in MEM medium without phenol red (Invitrogen), supplemented with $33 \mathrm{mM}$ glucose, $20 \mathrm{mM}$ HEPES, 2 mM glutamine, $1 \mathrm{mM}$ sodium pyruvate, and $2 \%$ B-27. Neurons expressing full-length mEos $4-G l y R \beta$ variants were imaged in Tyrode's solution (120 mM NaCl, 2.5 
$\mathrm{mM} \mathrm{KCl}, 2 \mathrm{mM} \mathrm{CaCl}_{2}, 2 \mathrm{mM} \mathrm{MgCl}_{2}, 30 \mathrm{mM}$ glucose, and 25 mM HEPES; pH 7.4). Before imaging, active synapses were loaded with FM 4-64 dye (Invitrogen). Coverslips were incubated for $45 \mathrm{~s}$ with imaging medium containing $1 \mu \mathrm{M} \mathrm{FM} \mathrm{4-64} \mathrm{and} 40 \mathrm{mM} \mathrm{KCl}$ and rinsed. Neurons were then imaged at $35^{\circ} \mathrm{C}$ for up to $40 \mathrm{~min}$. FM 4-64 was visualized with a mercury lamp $(560-\mathrm{nm}$ excitation and 684-nm emission filters) and bleached with a 561-nm laser before PALM imaging of Dendra2 or mEos4b fluorophores.

\section{Single particle tracking photo-activated localization microscopy (sptPALM)}

SPT using PALM relies on the reconstruction of molecule trajectories by connecting the positions of moving fluorophores in consecutive image frames. Live PALM imaging was performed on an inverted Nikon Ti Eclipse microscope. The $\beta$ L-TMD-Dendra2 and mEos $4 b-G l y R \beta$ variants were photo-converted from the green to the red state with a $405 \mathrm{~nm}$ laser (100 mW) and excited using $561-\mathrm{nm}$ illumination (laser output set to $200 \mathrm{~mW}$ ). The combined laser beams were led through an optical fiber into the TIRF arm of the microscope and focused in the rear plane of a $100 \times$ immersion objective (numerical aperture 1.49). Laser intensities were adjusted with an AOTF to detect a sparse number of fluorophores in each image and to record relatively long trajectories of at least five points. This was done using pulsed 405-nm laser illumination $(0.45$-pms pulses during the off-time of the camera) and moderate $561-\mathrm{nm}$ excitation intensity $(50 \%$ of laser output). Image stacks of 10,000 frames were acquired at a frame rate of $15 \mathrm{~ms}$ with an Andor iXon Ultra EMCCD camera (160-nm image pixel size). The $z$ position was maintained by a Nikon perfect focus system.

\section{Diffusion analysis}

Detection and tracking of $\beta$ L-TMD-Dendra2 variants were based on the MTT algorithm (Sergé et al., 2008), using a lab-made software (SPTrack v.4; Renner et al., 2017) running in Matlab (Mathworks). The center of each fluorophore signal was determined using a Gaussian fit, achieving a localization precision of $\sim 20 \mathrm{~nm}$. Only trajectories of at least five points without blinking were retained. Trajectories were classified as synaptic when they overlapped or were within two pixels $(320 \mathrm{~nm})$ of the FM 4-64 positive presynaptic terminals (image binarization using multidimensional wavelet decomposition (MIA; Racine et al., 2007). Values of mean squared displacement (MSD) were calculated for each trajectory as described (Ehrensperger et al., 2007). Effective diffusion coefficients $\left(D_{\text {eff }}\right)$ were calculated by fitting the second to the fourth time point of the MSD curves against time $(\tau)$ according to the equation MSD $=4 \mathrm{D} \tau$. For each trajectory of $N \geq 5$ detections, the explored area (normalized by the number of detections) was calculated as a measure of the molecule mobility. The area was defined as the smallest convex envelope containing all the coordinates $x_{i}$ and $y_{i}$ of the trajectory, where $1 \leq \mathrm{i} \leq \mathrm{N}$, calculated using the convex hull function in Matlab (Renner et al., 2017). The sptPALM recordings of full-length mEos $4 b-G l y R \beta$ variants were done at a later stage of the project, using a similar exper- imental procedure, with several modifications. Recordings were background-corrected by subtracting a minimal t-projection of the raw movie from each image frame. Detection and tracking were done with a newer MTTbased analysis software (SuperRes v.1; M. Renner, unpublished). Trajectories of a minimum of six detections (five steps) were considered for analysis, allowing for blinking of one frame. $D_{\text {eff }}$ was calculated by fitting the second to fifth time point of the MSD curve. Trajectories within a three-pixel distance $(480 \mathrm{~nm})$ of the FM 4-64 mask (binarized image using wavelet point detection, Icy analysis platform, Institut Pasteur; de Chaumont et al., 2012), were considered as synaptic.

\section{Statistical analysis}

Determination of binding parameters between $\beta \mathrm{L}$ variants and full-length gephyrin or GephE via ITC was repeated using independently expressed and purified proteins. Mean binding parameters and SEM values from a minimum of three individual measurements are given in the results. An unpaired two-tailed $t$ test was applied for statistical comparison via GraphPad Prism 5 and superscript letters within the results section are listed with $p$ values in Table 1. The effective diffusion of TMD- $\beta$ L and GlyR $\beta$ variants in spinal cord neurons was compared via one-way ANOVA (Kruskal-Wallis test). A post hoc Dunn's multiple comparison test was applied due to differences in the number of detected trajectories. The comparison of membrane diffusion of TMD- $\beta \mathrm{L}$ and GlyR $\beta$ variants was based on $n>700$ trajectories per condition from more than nine cells and three to five independent experiments (superscript letters in the results section are listed with $p$ values in Table 1).

\section{Results}

\section{Bimodal GlyR $\beta$-loop binding requires trimeric full-length gephyrin}

GlyR immobilization at the postsynaptic membrane crucially depends on gephyrin. A two-site binding mechanism of the GlyR $\beta$-loop (49 residues, 378-426) has been repeatedly identified using recombinant gephyrin expressed and purified from prokaryotic or eukaryotic organisms, suggesting an intrinsic feature of the interaction (Schrader et al., 2004; Sola et al., 2004; Herweg and Schwarz, 2012; Sander et al., 2013). Full-length gephyrin expressed in $E$. coli forms stable trimers (Schrader et al., 2004; Herweg and Schwarz, 2012; Sander et al., 2013), representing its basic oligomeric form. Within a trimer, the C-terminal E-domains are in a monomeric state (Sander et al., 2013). In contrast, isolated GephE domains expressed in E. coli form dimers at physiologic salt concentrations and $\mathrm{pH}$ 7.4-8.0 (data not shown). The binding pocket for the GlyR $\beta$-loop, formed at the interface of the two monomers, has been identified in the crystal structure of the GephE dimer (Sola et al., 2004; Kim et al., 2006).

To uncover the role of dimer formation for GlyR $\beta$-loop binding, we compared the behavior of dimeric and monomeric E-domain using GephE and full-length gephyrin, respectively. The biophysical properties of the interaction with the $\beta$-loop ( $\beta \mathrm{L}-\mathrm{wt}$, residues 378-426) were deter- 
Table 1. Statistical analysis of ITC binding parameters between gephyrin and GlyR $\beta$-loop variants and of sptPALM data of TMD- $\beta$ L and GlyR $\beta$ variants

\begin{tabular}{|c|c|c|c|}
\hline Line & Data structure & Type of test & Power \\
\hline a & Normal distribution & Unpaired two-tailed $t$ test & 0.0005 \\
\hline$b$ & Normal distribution & Unpaired two-tailed $t$ test & 0.0001 \\
\hline $\mathrm{c}$ & Normal distribution & Unpaired two-tailed $t$ test & 0.0008 \\
\hline d & Normal distribution & Unpaired two-tailed $t$ test & For $K_{\mathrm{D}} 0.3234 /$ for $\Delta \mathrm{H} 0.6921$ \\
\hline e & Normal distribution & Unpaired two-tailed $t$ test & $<0.0001$ \\
\hline$f$ & Normal distribution & Unpaired two-tailed $t$ test & $<0.0001$ \\
\hline g & Normal distribution & Unpaired two-tailed $t$ test & 0.0003 \\
\hline $\mathrm{h}$ & Normal distribution & Unpaired two-tailed $t$ test & 0.001 \\
\hline $\mathrm{i}$ & Normal distribution & Unpaired two-tailed $t$ test & 0.0267 \\
\hline j & Not normal distribution & One-way ANOVA/post hoc Bonferroni test & $>0.05$ \\
\hline $\mathrm{k}$ & Not normal distribution & $\begin{array}{l}\text { One-way ANOVA (Kruskal-Wallis test)/post hoc } \\
\text { Dunn's multiple comparison test }\end{array}$ & For areas $<0.001 /$ for $D_{\text {eff }}<0.001$ \\
\hline I & Not normal distribution & $\begin{array}{l}\text { One-way ANOVA (Kruskal-Wallis test)/post hoc } \\
\text { Dunn's multiple comparison test }\end{array}$ & For areas $<0.001 /$ for $D_{\text {eff }}<0.001$ \\
\hline $\mathrm{m}$ & Not normal distribution & $\begin{array}{l}\text { One-way ANOVA (Kruskal-Wallis test)/post hoc } \\
\text { Dunn's multiple comparison test }\end{array}$ & For areas $<0.001 /$ for $D_{\text {eff }}<0.001$ \\
\hline $\mathrm{n}$ & Not normal distribution & $\begin{array}{l}\text { One-way ANOVA (Kruskal-Wallis test)/post hoc } \\
\text { Dunn's multiple comparison test }\end{array}$ & $<0.001$ \\
\hline o & Not normal distribution & $\begin{array}{l}\text { One-way ANOVA (Kruskal-Wallis test)/post hoc } \\
\text { Dunn's multiple comparison test }\end{array}$ & For areas $p<0.001 /$ for $D_{\text {eff }} p<0.001$ \\
\hline $\mathrm{p}$ & Not normal distribution & $\begin{array}{l}\text { One-way ANOVA (Kruskal-Wallis test)/post hoc } \\
\text { Dunn's multiple comparison test }\end{array}$ & For areas $<0.0001 /$ for $D_{\text {eff }}<0.0001$ \\
\hline
\end{tabular}

ITC-derived binding parameters from a minimum of three independent measurements were compared using an unpaired two-tailed $t$ test. Diffusion values were compared via one-way ANOVA (Kruskal-Wallis test) followed by a post hoc Dunn's multiple comparison test. The comparison test was applied due to differences in the number of detected trajectories $(n=700-10,000$ synaptic trajectories for each construct from three to five independent experiments).

mined by ITC. GephE or full-length gephyrin were applied in the sample cell and sequentially titrated with $\beta \mathrm{L}-\mathrm{wt}$ peptide (Fig. 1). We identified an exothermic interaction between GephE and $\beta$ L-wt (Fig. 1A; Table 2). Unlike previous studies (Schrader et al., 2004; Sola et al., 2004), we could only fit the raw data to a one-site binding model (Fig. 1B). The averaged binding stoichiometry indicated a $50 \%$ occupancy of binding sites in GephE. In contrast to the interaction with dimeric E-domain, the binding isotherms of full-length gephyrin (Fig. 1C) were best fitted using a two-site model displaying two distinguishable binding events with $\beta$ L-wt (Fig. $1 D, E$ ). Lowering the $\mathrm{pH}$ has been found to induce gephyrin oligomerization (Sola et al., 2004). To exclude a possible effect on $\beta \mathrm{L}-\mathrm{wt}$ binding, we performed control experiments in which the $\mathrm{pH}$ was reduced from 8.0 to 7.4 (Fig. 1F). No significant changes in the ITC parameters were observed, confirming that high- and low-affinity binding occurs under physiologic conditions. Although both sites exhibited exothermic binding, the enthalpy reflecting the heat release differed significantly between the two sites (Fig. 1C; Table 3; $p=$ $0.0005)^{\mathrm{a}}$. This is in line with earlier data (Schrader et al., 2004; Specht et al., 2011; Herweg and Schwarz, 2012) that showed that the $K_{\mathrm{D}}$ values of high- and low-affinity sites differed by two orders of magnitude (Fig. 1D). The molar ratios confirmed the presence of one high- and two low-affinity sites per gephyrin trimer (Specht et al., 2011; Herweg and Schwarz, 2012) and suggested that monomeric and dimeric E-domains undergo diverging binding events with the GlyR $\beta$-loop. Bimodal binding thus appears to be a unique property of full-length gephyrin.

\section{$\mathrm{N}$ - and $\mathrm{C}$-terminal sequences flanking the GlyR $\beta$-loop core domain tune gephyrin binding}

The identification of two distinguishable binding modes of gephyrin raises the question about the nature of the bimodal interaction on the GlyR side. We therefore studied the molecular determinants within the GlyR $\beta$-loop peptide (residues 378-426) that was shown to interact with full-length gephyrin with high and low affinity.

The GlyR $\beta$-loop-GephE crystal structure identified residues 398-410 as core binding sequence of the GlyR $\beta$-loop (Kim et al., 2006). We first used a 20-residue peptide ( $\beta$ L-Core: residues 394-413) to narrow down the residues involved in bimodal binding (Fig. $2 A, B$ ). Surprisingly, the ITC traces of $\beta \mathrm{L}$-Core only displayed partial binding to full-length gephyrin with significantly less heat release $(\Delta \mathrm{H})$ as compared to the high-affinity site of the longer 49 residue loop (Figs. $1 C, D, 2 C, D$; Table 3; $p=$ $0.0001)^{\mathrm{b}}$, reflecting a reduction in binding affinity $(p=$ $0.0008)^{c}$ and the number of interacting residues. To restore high- and low-affinity interactions, either the $\mathrm{N}$-terminal ( $\beta$ L-LO: 378-413) or C-terminal residues ( $\beta$ L-HI: 394-426) of the 49-residue $\beta \mathrm{L}$-wt peptide were attached separately to $\beta \mathrm{L}$-Core (Fig. $2 A$ ). Although neither the $\mathrm{N}$ - nor the $\mathrm{C}$-terminal extensions were able to induce two-site binding with gephyrin on their own, they had pronounced effects on the binding properties of the core sequence (Fig. $2 C, D$ ). $\mathrm{N}$-terminal extension of $\beta \mathrm{L}$-Core led to a similar binding behavior to gephyrin as $\beta \mathrm{L}$-Core alone (Table 3; Fig. 2D; $\left.K_{\mathrm{D}} p=0.3234, \Delta \mathrm{H} p=0.6921\right)^{\mathrm{d}}$. The binding stoichiometry, however, was significantly increased, indicating a higher occupancy of gephyrin in the 
A

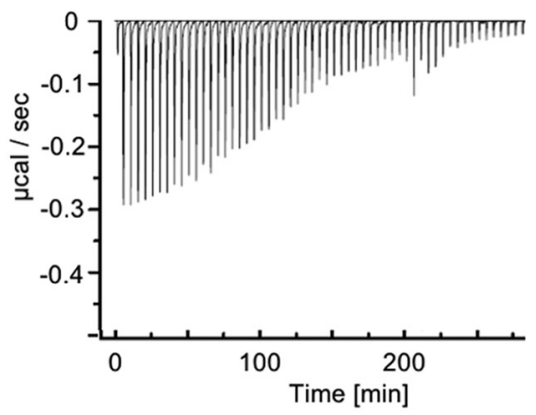

C

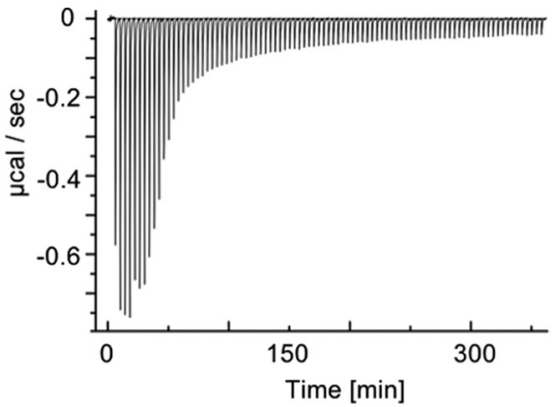

E

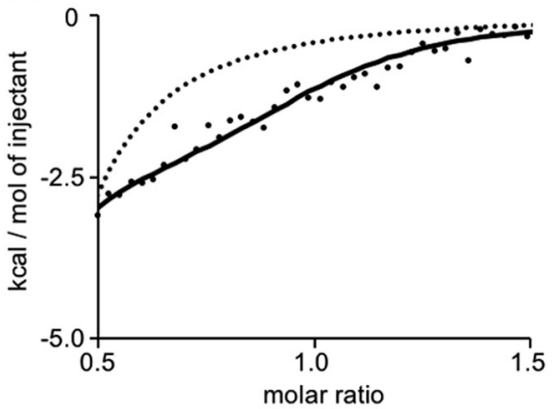

B

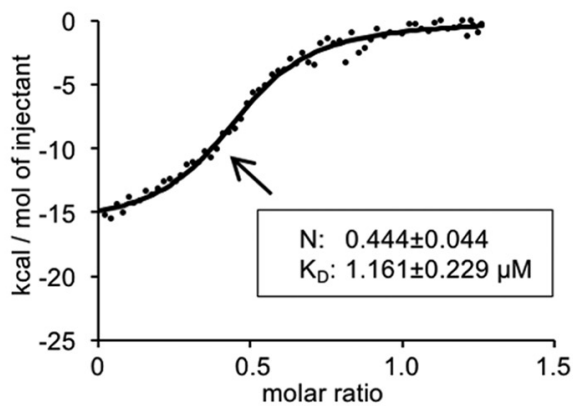

D

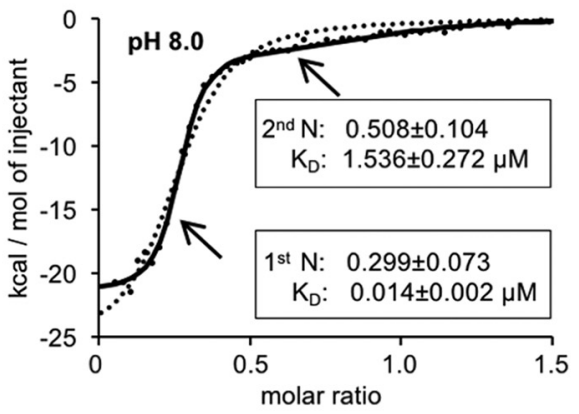

F

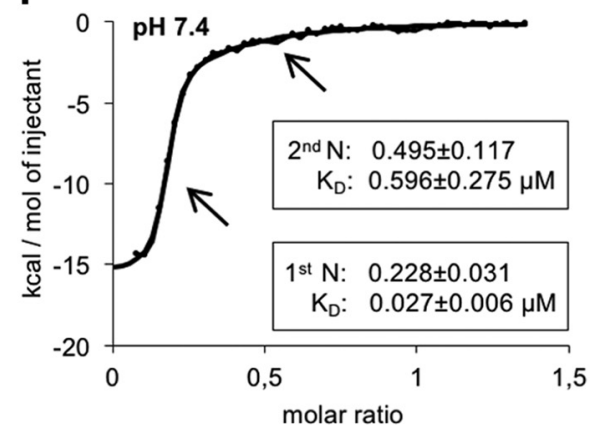

Figure 1. Binding properties of GlyR $\beta$-loop to full-length gephyrin or the isolated E-domain. $\boldsymbol{A}$, Representative ITC titration profile of $\beta \mathrm{L}-$ wt $(378-426 ; 281 \mu \mathrm{M})$ into GephE $(31 \mu \mathrm{M})$ at $\mathrm{pH}$ 8.0. The recorded peaks were corrected by baseline-corrected injection heats. $\boldsymbol{B}$, Binding isotherms (dots) of integrated binding heats were fitted to a one-site model (black line). The average dissociation constant $\left(K_{\mathrm{D}}\right)$ and binding stoichiometry with GephE $(\mathrm{N})$ of five independent experiments are given. $\boldsymbol{C}$, Representative ITC titration profile of $\beta \mathrm{L}$-wt $(327 \mu \mathrm{M})$ into gephyrin $(29 \mu \mathrm{M})$. $\boldsymbol{D}$, Binding isotherm (dots) of integrated binding heats were fitted to a two-site model (black line) or a one-site model (dotted line). An individual measurement of $\beta \mathrm{L}$-wt binding to gephyrin is shown alongside with averaged thermodynamic parameters of both sites (binding stoichiometry $\mathrm{N}$ and dissociation constant $\left.K_{\mathrm{D}}\right)$. Binding enthalpies $(\Delta \mathrm{H}$ in $\mathrm{kcal} / \mathrm{mol}$ ) for $\beta \mathrm{L}$-wt high and low affinity were compared using an unpaired two-tailed $t$ test: $p=0.0005 \beta \mathrm{L}$-wt high-affinity site $n=3$ versus $\beta \mathrm{L}$-wt low-affinity site $n=3$. $\boldsymbol{E}$, Magnification of the graph represented in $\boldsymbol{D}$, showing the fitted curves of the binding isotherm of $\beta \mathrm{L}$-wt and gephyrin (dots) derived from the two-site (black line) or the one-site (dotted line) binding model. $\boldsymbol{F}$, ITC data showing the bimodal binding between $\beta \mathrm{L}-w \mathrm{t}$ and gephyrin at $\mathrm{pH}$ 7.4. Binding isotherms of $\beta \mathrm{L}-w \mathrm{t}(378-426 ; 248 \mu \mathrm{M})$ into gephyrin $(28.6 \mu \mathrm{M})$ at $\mathrm{pH} 7.4$. Binding isotherms (dots) of integrated binding heats were fitted to a two-site model (black line). An individual measurement of $\beta \mathrm{L}-\mathrm{wt}$ binding to gephyrin is shown alongside with averaged thermodynamic parameters of both sites (binding stoichiometry $\mathrm{N}$ and dissociation constant $K_{\mathrm{D}}$ ). Binding affinities and enthalpies for $\beta \mathrm{L}$-wt high- and low-affinity binding sites at $\mathrm{pH} 8.0$ and 7.4 were compared using an unpaired two-tailed $t$ test: $p=0.2143 K_{\mathrm{D}} \beta \mathrm{L}$-wt high-affinity sites $n=3 ; p=0.0958 K_{\mathrm{D}} \beta \mathrm{L}$-wt low-affinity sites $n=3 ; p=0.1889$ $\Delta \mathrm{H} \beta \mathrm{L}$-wt high-affinity sites $n=3 ; p=0.0849 \Delta \mathrm{H} \beta \mathrm{L}$-wt low-affinity sites $n=3$.

presence of the $\mathrm{N}$-terminal residues (Fig. 2D; $p<$ $0.0001)^{e}$. The $\mathrm{C}$-terminal extension of the $\beta$ L-Core sequence resulted in a strong increase of heat release when titrated to gephyrin (Fig. 2C,D; Table 3; $p<0.0001$ ) ${ }^{f}$. This increase in binding enthalpy was reflected in a significantly higher affinity $(p=0.0003)^{9}$ and a lower stoichiometry $(p=0.001 \text {; Fig. } 2 D)^{\mathrm{h}}$, resembling the high-affinity interaction of $\beta$ L-wt with gephyrin at one of the three available binding sites in trimeric gephyrin (Fig. 1D). These results highlight that high-affinity binding to gephyrin was significantly restored by the presence of C-terminal extension in $\beta \mathrm{L}-\mathrm{HI}$. A full rescue of $\beta \mathrm{L}-\mathrm{wt}$ high-affinity binding to gephyrin requires the presence of both low- and high-affinity sites (Figs. 1D, 2D ). 
Table 2. Gephyrin E-domain binding enthalpy and binding entropy of GlyR $\beta$-loop wild-type determined by ITC

\begin{tabular}{lll}
\hline Parameter & $\beta$-Loop variant & One-site model $^{4}$ \\
$\Delta \mathrm{H}[\mathrm{kcal} / \mathrm{mol}]^{1}$ & $\beta$ L-wt $^{3}$ & $-16.1 \pm 0.5$ \\
$\Delta \mathrm{S}[\mathrm{cal} / \mathrm{mol} * \mathrm{~K}]^{2}$ & $\beta$ L-wt $^{3}$ & $-26.8 \pm 2.1$ \\
\hline
\end{tabular}

Mean values and SEM from five independent measurements. ${ }^{1}$ Binding enthalpy $(\Delta \mathrm{H}$ in $\mathrm{kcal} / \mathrm{mol}) ;{ }^{2}$ binding entropy $(\Delta \mathrm{S}$ in cal $/ \mathrm{mol} * \mathrm{~K}) ;{ }^{3}$ GlyR $\beta$-loop residues $378-426 ;{ }^{4}$ binding isotherm fitted to a one-site interaction with gephyrin E-domain.

Taken together, our ITC studies identified two different sequences within the GlyR $\beta$-loop that contribute to highand low-affinity interactions with gephyrin, respectively (Fig. 2A). Within trimeric full-length gephyrin, each E-domain offers one binding site, of which one has a high and two have a low affinity (Fig. 1D; Specht et al., 2011; Herweg and Schwarz, 2012). These sequences were found to be located outside of the $\beta \mathrm{L}$-Core region (Sola et al., 2004; Kim et al., 2006), demonstrating the impact of the flanking sequences of the GlyR $\beta$-loop for gephyrin association.

\section{The GlyR $\beta$-loop $\mathbf{N}$ terminus extends the gephyrin binding site}

The 49-residue $\beta \mathrm{L}$-wt comprises high- and low-affinity sites for gephyrin interaction. However, the crystal structure of the GephE- $\beta \mathrm{L}$ complex only revealed the interface of $\beta \mathrm{L}-$ Core (Kim et al., 2006). Based on our previous results, we now aimed at identifying the additional gephyrin regions that participate in the bimodal binding. To this aim, we applied a chemical crosslinking approach using EDC. Using EDC, two proteins may be fixed without a spacer, indicating a close proximity of the crosslinked residues. The purified full-length gephyrin and $\beta \mathrm{L}-w \mathrm{t}$ peptide were incubated with EDC and subsequently subjected to SDS-PAGE (Fig. 3A). Addition of EDC resulted in a shift of the protein band to higher molecular weights, representing a fraction of dimeric (lower band) and trimeric (upper band) full-length gephyrin (Schrader et al., 2004; Herweg and Schwarz, 2012; Sander et al., 2013). The band corresponding to trimer was extracted and

A

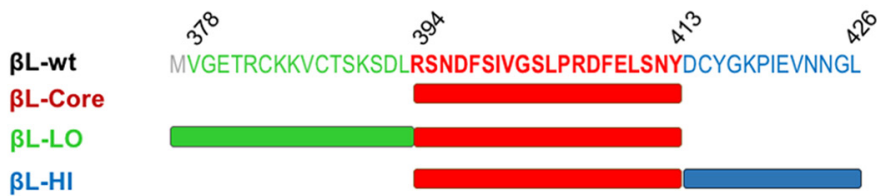

$\otimes^{0} \quad$ B
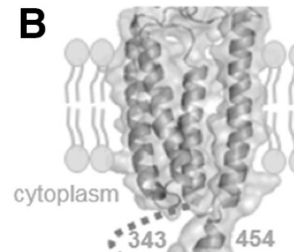
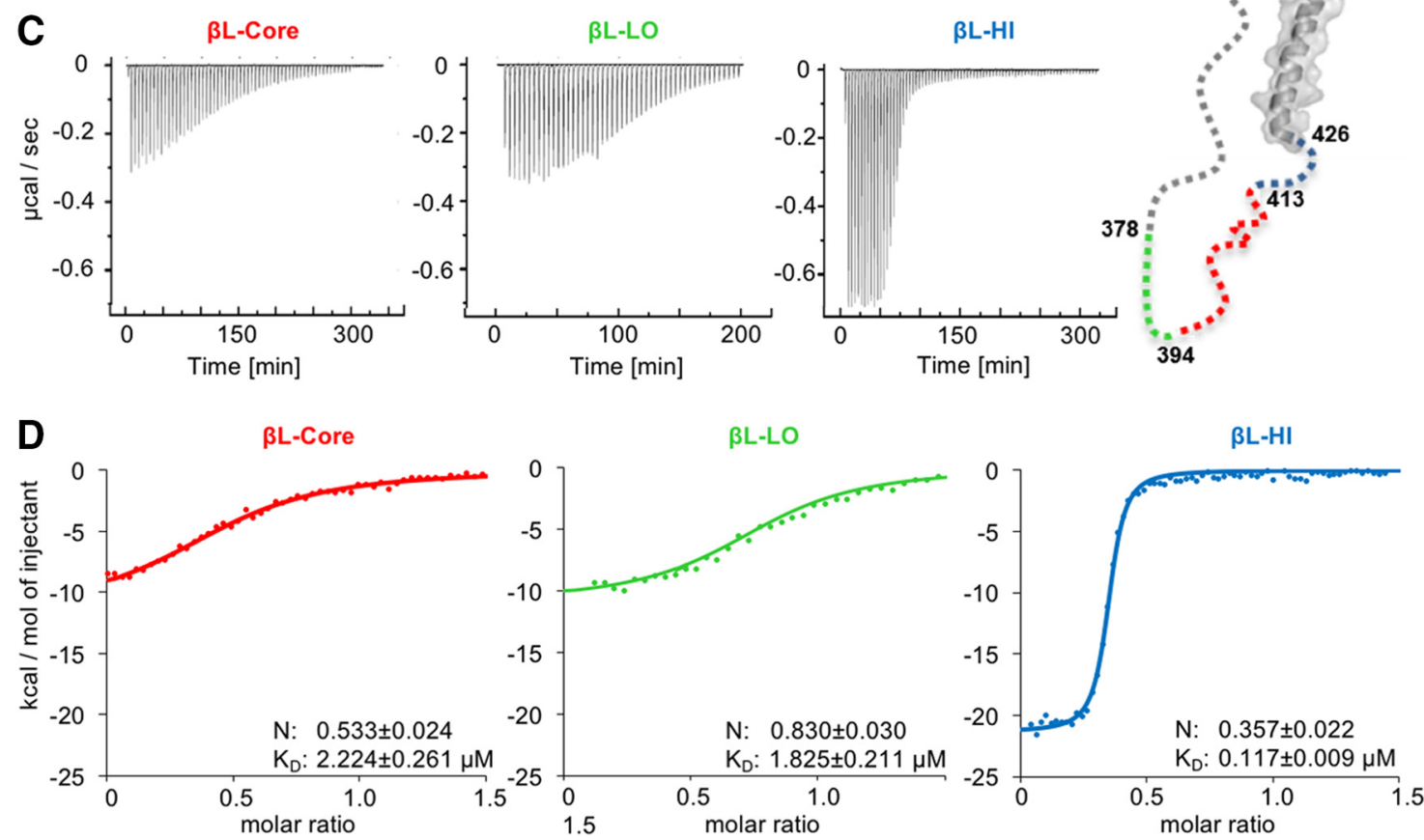

Figure 2. Dissection of the bimodal binding between GlyR $\beta$ and gephyrin. A, GlyR $\beta$-loop peptides include full-length $\beta \mathrm{L}^{378-426}$ ( $\beta \mathrm{L}-\mathrm{wt}), \mathrm{C}$-terminal $(\beta \mathrm{L}-\mathrm{LO}$, green), and $\mathrm{N}$-terminal $(\beta \mathrm{L}-\mathrm{HI}$, blue) truncations as well as a core region $(\beta \mathrm{L}-\mathrm{Core}$, red). $\boldsymbol{B}$, Structural model of the GlyR $\beta$-subunit based on the crystal structure of the nicotinic acetylcholine receptor (Unwin, 2005). Structural information corresponding to GlyR $\beta$ residues 343-426 of the ICD is lacking and therefore depicted with a dashed line. The position of the analyzed GlyR $\beta$-loop peptides is depicted. $\boldsymbol{C}$, Representative ITC titration profiles of $\beta \mathrm{L}-\mathrm{Core}, \beta \mathrm{L}-\mathrm{LO}$, and $\beta \mathrm{L}-\mathrm{HI}$ (250-300 $\mu \mathrm{M}$ each) to 20-30 $\mu \mathrm{M}$ gephyrin under similar conditions. $\boldsymbol{D}$, Fitting of the ITC binding isotherms (dots) of $\beta \mathrm{L}-\mathrm{Core}$, $\beta \mathrm{L}-\mathrm{LO}$, and $\beta \mathrm{L}-\mathrm{HI}$ to a one-site binding model (colored traces). Representative recordings are shown together with averaged $K_{\mathrm{D}}$ values and binding stoichiometry with gephyrin $(\mathrm{N})$. Data were compared using an unpaired two-tailed $t$ test: $p=0.0008 K_{\mathrm{D}}$ of $\beta \mathrm{L}$-wt high-affinity site $n=3$ versus $\beta \mathrm{L}$-Core $n=9 ; p=0.3234 K_{\mathrm{D}}$ of $\beta \mathrm{L}$-Core $n=9$ versus $\beta \mathrm{L}-\mathrm{LO} n=5 ; p<0.0001 \mathrm{~N}$ of $\beta \mathrm{L}-$ Core $n=9$ versus $\beta \mathrm{L}-\mathrm{LO} n=5 ; p=0.0003 K_{\mathrm{D}}$ of $\beta \mathrm{L}$-Core $n=9$ versus $\beta \mathrm{L}-\mathrm{HI} n=4 ; p=0.001 \mathrm{~N}$ of $\beta \mathrm{L}-\mathrm{Core} n=9$ versus $\beta \mathrm{L}-\mathrm{HI} n=4$. 
Table 3. Gephyrin binding enthalpies and binding entropies of GlyR $\beta$-loop variants determined by ITC

\begin{tabular}{|c|c|c|c|c|}
\hline \multirow[t]{2}{*}{ Parameter } & \multirow[t]{2}{*}{$\beta$-Loop variant } & \multicolumn{2}{|l|}{ Two-site model $^{9}$} & \multirow[t]{2}{*}{ One-site model ${ }^{10}$} \\
\hline & & High-affinity site & Low-affinity site & \\
\hline \multirow[t]{6}{*}{$\Delta \mathrm{H}[\mathrm{kcal} / \mathrm{mol}]^{1}$} & $\beta$ L-wt (pH 8.0) & $-19.2 \pm 1.6$ & $-2.1 \pm 0.3 * * *$ & - \\
\hline & $\beta \mathrm{L}-\mathrm{LO}^{4}$ & - & - & $-11.8 \pm 2.5$ \\
\hline & $\beta$ L-Core ${ }^{5}$ & - & - & $-11.0 \pm 0.6 * * *$ \\
\hline & $\beta \mathrm{L}-\mathrm{HI}{ }^{6}$ & - & - & $-21.5 \pm 0.3 * * *$ \\
\hline & $\beta$ L-D407P/F408G ${ }^{7}$ & - & - & $-13.8 \pm 3.2$ \\
\hline & $\beta \mathrm{L}-\mathrm{wt}(\mathrm{pH} 7.4)^{8}$ & $-14.2 \pm 1.9$ & $-4.9 \pm 0.9$ & - \\
\hline \multirow[t]{6}{*}{$\Delta \mathrm{S}[\mathrm{cal} / \mathrm{mol} * \mathrm{~K}]^{2}$} & $\beta \mathrm{L}-\mathrm{wt}(\mathrm{pH} 8.0)^{3}$ & $-28.4 \pm 5.3$ & $19.5 \pm 1.4$ & - \\
\hline & $\beta \mathrm{L}-\mathrm{LO}^{4}$ & - & - & $-6.7 \pm 3.5$ \\
\hline & $\beta$ L-Core $^{5}$ & - & - & $-11.2 \pm 2.0$ \\
\hline & $\beta \mathrm{L}-\mathrm{HI}{ }^{6}$ & - & - & $-40.3 \pm 1.1$ \\
\hline & $\beta \mathrm{L}-\mathrm{D} 407 \mathrm{P} / \mathrm{F} 408 \mathrm{G}^{7}$ & - & - & $-21.7 \pm 11$ \\
\hline & $\beta$ L-wt $(\mathrm{pH} 7.4)^{8}$ & $-14.2 \pm 6.3$ & $8.3 \pm 4.2$ & - \\
\hline
\end{tabular}

Mean values and SEM from three or more independent measurements. ${ }^{1}$ binding enthalpy $(\Delta \mathrm{H}$ in $\mathrm{kcal} / \mathrm{mol}) ;{ }^{2}$ binding entropy $(\Delta \mathrm{S}$ in $\mathrm{cal} / \mathrm{mol} * \mathrm{~K}) ;{ }^{3} \mathrm{GlyR}$ $\beta$-loop residues $378-426, \mathrm{pH} 8.0 ;{ }^{4}$ GlyR $\beta$-loop residues $378-413 ;{ }^{5}$ GlyR $\beta$-loop residues $394-413 ;{ }^{6}$ GlyR $\beta$-loop residues $394-426 ;{ }^{7}$ GlyR $\beta$-loop residues 378-426 with substitution D407P and F408G; ${ }^{8}$ GlyR $\beta$-loop residues $378-426$, $\mathrm{pH} 7.4$; ${ }^{9}$ binding isotherm fitted to a two-site interaction with gephyrin;

${ }^{10}$ binding isotherm fitted to a one-site model; Data were compared using an unpaired two-tailed $t$-test: $* * * p=0.0005 \Delta \mathrm{H}$ of $\beta \mathrm{L}$-wt high-affinity site $n=3$ vs. low-affinity site $n=3 ; * * * p=0.0001 \Delta \mathrm{H}$ of $\beta \mathrm{L}$-wt high-affinity site $n=3$ vs. $\beta \mathrm{L}$-Core $n=9 ; * * * p<0.0001 \Delta \mathrm{H}$ of $\beta \mathrm{L}-\mathrm{Core} n=9$ vs. $\beta \mathrm{L}-\mathrm{HI} n=4 ; p=$ $0.6921 \Delta \mathrm{H}$ of $\beta \mathrm{L}-$ Core $n=9$ vs. $\beta \mathrm{L}-\mathrm{LO} n=5$.

further analyzed by mass spectrometry to identify gephyrin- $\beta \mathrm{L}-w \mathrm{wt}$ fragments. We found many overlapping peptides, covering $\beta \mathrm{L}$ residues $378-394$, crosslinked to different gephyrin peptides located in the $\mathrm{C}$ - and E-domains (Fig. 3B,C). One particular peptide of the gephyrin E-domain (residues 329-348) served to validate our approach, since it contains residue Phe330. This residue is known to create a hydrophobic pocket together with Phe398 and lle400 of the GlyR $\beta$ L that is required for their interaction (Kneussel et al., 1999; Kim et al., 2006). Another peptide of the gephyrin E-domain was crosslinked to an $\mathrm{N}$-terminal fragment of the $\beta \mathrm{L}$ (residues 378390). Given the increase in gephyrin occupancy on attaching these residues to $\beta \mathrm{L}-$ Core (residues 394-413; Fig. $2 A, D$ ), our finding supports an extended interaction interface of the $\beta \mathrm{L} N$-terminal sequence $(\beta \mathrm{L}-\mathrm{LO})$ and gephyrin. Interestingly, in addition to the E-domain, several peptides of the $\mathrm{C}$-domain were crosslinked to $\mathrm{N}$-terminal $\beta \mathrm{L}$ residues (Fig. 3B,C).

Based on our results, we established a model of fulllength trimeric gephyrin interacting with the the GlyR $\beta$-loop (Fig. 3C,D) using a previously reported structural model of gephyrin (Belaidi and Schwarz, 2013). In the absence of structural information of the $\beta \mathrm{L}$-extensions, we indicated the proposed position of residues 378-397 (green) and 411-426 (blue) with dashed lines, according to the identified peptides (Fig. 3D). Crosslinked peptides in the gephyrin E-domain (Fig. $3 C, D$, highlighted in purple) undergo close contacts with the $\mathrm{N}$-terminal flanking region of the $\beta$-loop (shown in green), in addition to the core sequence (shown in red). Due to the localization of the peptides along the surface of the E-domain, we propose an elongated binding pocket on gephyrin occupied by $\mathrm{N}$-terminal residues of the GlyR $\beta$-loop (Fig. 3D).

High-affinity gephyrin binding was only restored following the attachment of $\mathrm{C}$-terminal $\beta$-loop residues (414426). However, we could not identify a contact site of these residues on gephyrin with our crosslinking approach. The C-terminal region is therefore likely to shape the binding of the $\beta$-loop to gephyrin without participating in the interaction itself.

\section{The GlyR $\beta$-loop C-terminal $3_{10}$-helix is required for high-affinity binding to gephyrin}

To exclude a direct interaction of the C-terminal flanking sequence with gephyrin, we tested a fragment spanning residues 409-426 in an additional ITC experiment with gephyrin (Fig. 4A). Only residual heat release could be detected, indicating that it is the fusion of these residues to $\beta \mathrm{L}$-Core that turns the fragment into a highaffinity binding peptide (Fig. 2). An increase in gephyrinbinding affinity of the core sequence could therefore be a consequence of conformational changes initiated by the $\mathrm{C}$-terminal flanking sequence of the $\beta$-loop. The crystal structure of the GephE dimer in complex with the $\beta$-loop showed a helical conformation between residues 406 and 411 (Fig. 4B) with features of a $3_{10}$-helix (Kim et al., 2006).

Purified $\beta \mathrm{L}-\mathrm{wt}$ was subjected to structural analysis via CD spectroscopy, and the resulting mean residue ellipticity was plotted against the respective wavelength (Fig. $4 C)$. The typical shape of a $3_{10}$-helix CD spectrum with minima at 208 and $220 \mathrm{~nm}$ confirmed the presence of this secondary structure element of $\beta \mathrm{L}-\mathrm{wt}$ in solution (Biron et al., 2002). The $\beta \mathrm{L}$-wt peptide contains residues that were found to be highly abundant in $3_{10}$-helices (Karpen et al., 1992). to interfere with the helical conformation, Asp407 and Phe408 were exchanged to Pro and Gly, respectively, both being less frequent in $3_{10}$-helices. CD spectroscopy of the $\beta$ L-D407P/F408G peptide showed a decrease in the intensity of the 208-nm minimum, confirming that the secondary structure in $\beta \mathrm{L}-\mathrm{D} 407 \mathrm{P} / \mathrm{F} 408 \mathrm{G}$ was affected (Fig. 4C). The direct comparison of the ITC binding curve with $\beta \mathrm{L}$-wt showed a reduction in heat release on titration to gephyrin (Fig. $4 D$; Table 3). Moreover, the resulting raw data could only be fitted to a one-site binding model (Fig. 4D). The obtained thermodynamic binding data for $\beta$ L-D407P/F408G revealed a significant reduction in binding affinity $(p=0.0267)^{i}$, 
A B
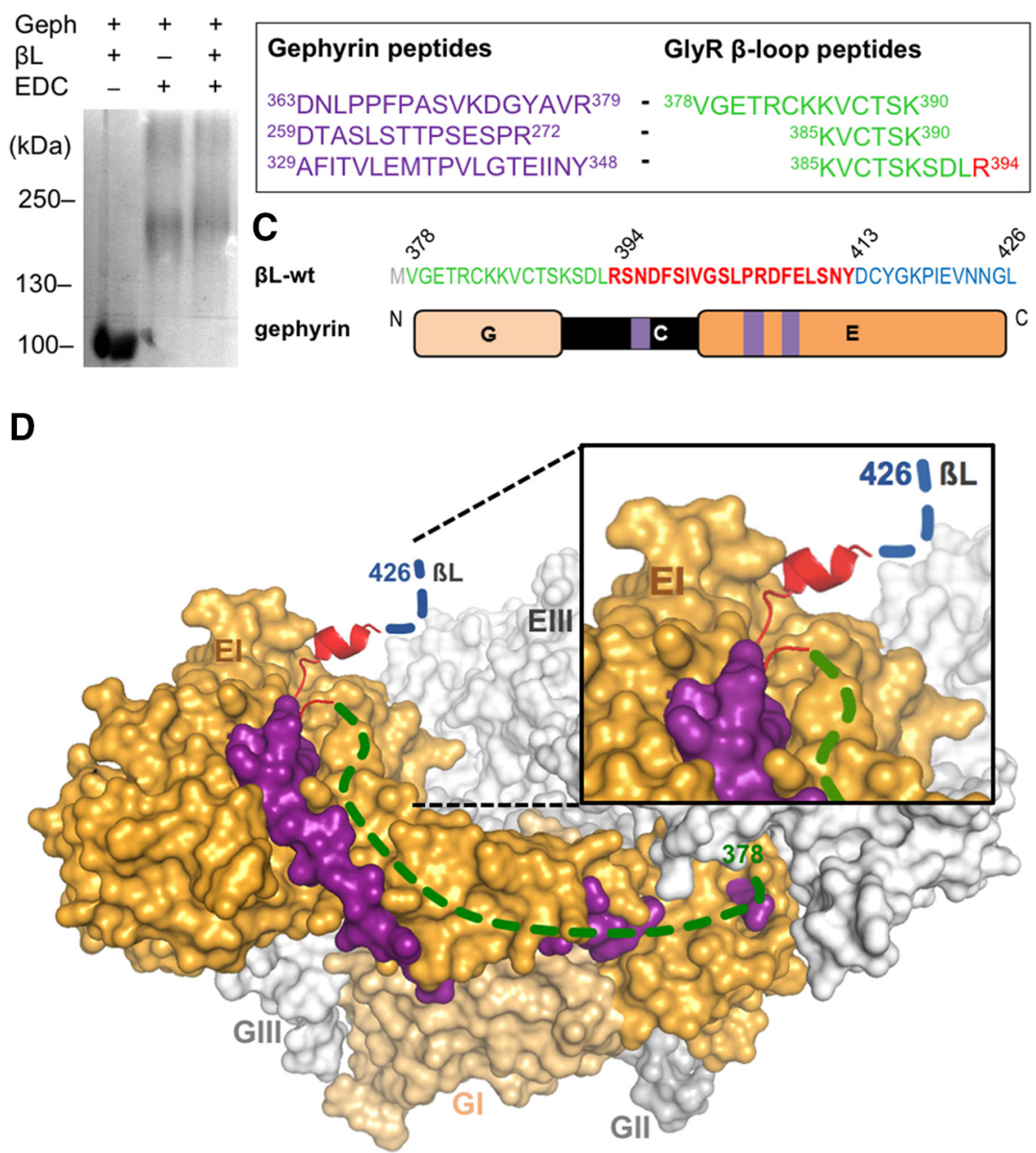

Figure 3. Extension of the GlyR $\beta$ binding site on gephyrin. A, EDC-based crosslinking of $\beta$ L-wt (378-426) and gephyrin. Gephyrin (Geph) and GlyR $\beta$-loop $(\beta \mathrm{L}$ ) were treated (lanes 2 and 3) or not treated (lane 1) with EDC and separated by $6 \%$ SDS-PAGE (Coomassie staining). B, Identification of crosslinked peptides. Bands corresponding to the protein complexes shown in $\boldsymbol{A}$ were extracted and analyzed by peptide mass fingerprinting. The crosslinked peptides of gephyrin (purple) and the $\beta$-loop (green, red) were identified several times. $\boldsymbol{C}$, Amino acid sequence of $\beta \mathrm{L}$-wt with the localization of N- (green, 378-393) and C-terminal (blue, 414-426) flanking sequences of the core gephyrin-binding site (red, 394-426). Schematic representation of gephyrin domains with highlighted positions of identified peptides in the C- and E-domain (purple). $\boldsymbol{D}$, Surface representation of a modeled trimeric full-length gephyrin (modified from (Belaidi and Schwarz, 2013) with highlighted peptides identified in the crosslinked gephyrin-GlyR $\beta$-loop complex. Dashed lines indicate regions in the $\beta \mathrm{L}$ for which structural information is lacking. Gephyrin protomer II and III: light gray; protomer I: E-domain, orange and G-domain, light orange; $\beta \mathrm{L}$ core sequence: red; $\beta \mathrm{L} N$-terminal flanking sequence: green; $\beta \mathrm{L} \mathrm{C}$-terminal flanking sequence: blue; and crosslinked peptides of the gephyrin E-domain: purple.

accompanied by a residual binding stoichiometry (Fig. $4 D$ ). This result suggests that the introduced mutations have a strong impact on the GlyR $\beta$-loop conformation, thus impacting the binding to gephyrin. Furthermore, the binding parameters of $\beta$ L-D407P/F408G show an additional loss of low-affinity interactions with gephyrin, strengthening the notion that both binding sites depend on one another.

\section{Impact of high- and low-affinity binding on GlyR diffusion trapping at synapses}

Our ITC experiments showed that $\mathrm{N}$ - and $\mathrm{C}$-terminal flanking sequences of the GlyR $\beta$-loop core region are responsible for the low- and high-affinity interaction with gephyrin, respectively. To explore the effects of bimodal binding on the physiological behavior of GlyRs at synaptic gephyrin clusters, we made use of SPT of GlyR $\beta$-loop constructs using PALM in living neurons. This approach is based on the sequential stochastic conversion of photoswitchable fluorophores to follow the movement of single molecules in subsequent image frames (sptPALM; Manley et al., 2008). The tracking of fluorophores at high spatial ( $\sim 50 \mathrm{~nm}$ in our experiments) and temporal resolution (15 $\mathrm{ms}$ ) gives access to diffusion parameters that reflect the strength of molecular interactions within specific membrane compartments (Specht et al., 2011).

We first compared the diffusion of membrane proteins consisting of $\beta$-loop sequences attached to a single TM 


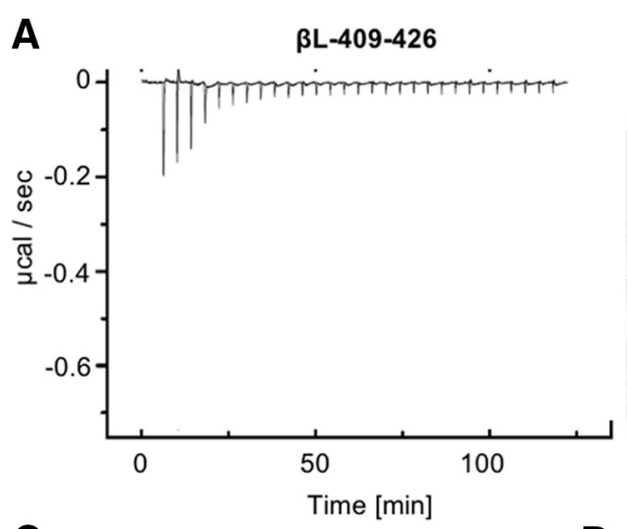

B
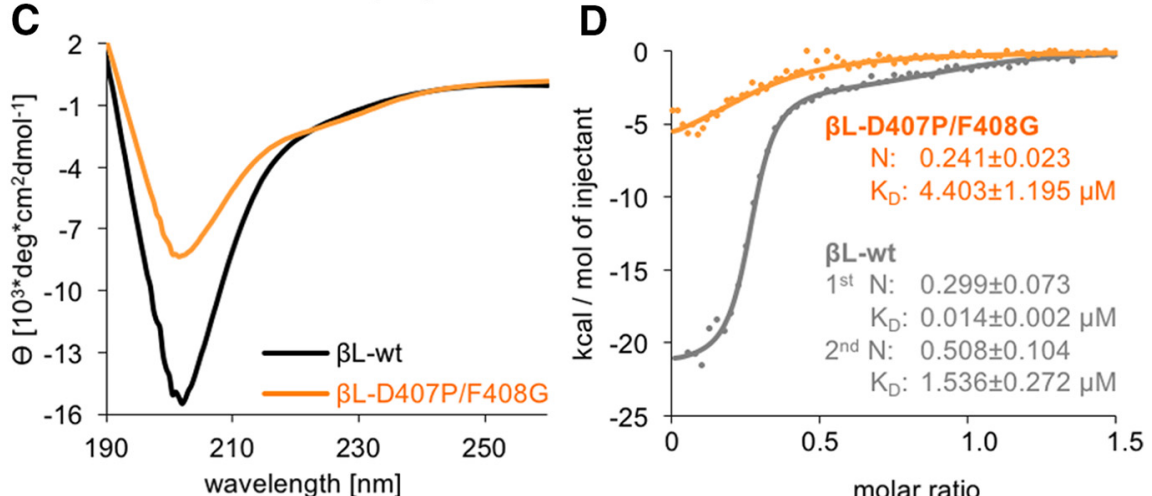

Figure 4. Impact of the GlyR $\beta$-loop conformation on gephyrin binding. $\boldsymbol{A}$, ITC titration profile of $\beta \mathrm{L}^{409-426}(445 \mu \mathrm{M})$ into gephyrin $(25 \mu \mathrm{M})$. $\boldsymbol{B}$, The GlyR $\beta$-loop in association with GephE adopts a short $33_{10}$-helix formed by residues $406-410$ (Kim et al., 2006 ). Two residues, Asp407 and Phe408, were mutated to proline and glycine ( $\beta \mathrm{L}-\mathrm{D} 407 \mathrm{P} / \mathrm{F} 408 \mathrm{G})$ to block the formation of the $3_{10}$-helix. $\boldsymbol{C}, \beta \mathrm{L}-\mathrm{wt}$ and $\beta \mathrm{L}-\mathrm{D} 407 \mathrm{P} / \mathrm{F} 408 \mathrm{G}$ (both $0.21 \mathrm{mg} / \mathrm{ml}$ ) folding was compared by CD spectroscopy. The mean residue ellipticity $(\theta)$ was plotted against the respective wavelength. $\boldsymbol{D}$, Comparison of the binding isotherms of representative measurements using $327 \mu \mathrm{M} \beta \mathrm{L}$-wt peptide (gray dots, same data as in Fig. $1 D, E$ ) and $315 \mu \mathrm{M} \beta \mathrm{L}-\mathrm{D} 407 \mathrm{P} / \mathrm{F} 408 \mathrm{G}$ (orange dots) with 29 or $32 \mu \mathrm{M}$ gephyrin, respectively. Curve calculation was performed based on a two-site model for $\beta$ L-wt (gray line) and a one-site model for $\beta$ L-D407P/F408G (orange line). Data were compared using an unpaired two-tailed $t$ test: $p=0.0267 K_{\mathrm{D}}$ of $\beta$ L-wt high-affinity site $n=3$ versus $\beta$ L-D407P/F408G $n=4$.

and an extracellular Dendra2 fluorophore, thus acting as random scanners of the neuronal membrane (Specht et al., 2011). The wild-type TMD- $\beta$ L-wt construct was strongly confined at synaptic gephyrin clusters, as judged by the accumulation of trajectories within FM 4-64 positive membrane domains (Fig. $5 A$ ). In contrast, a $\beta$-loop variant (TMD- $\beta$ L-geph ${ }^{-}$) in which gephyrin-binding was abolished by the introduction of the point mutations F398A/I400A (Kim et al., 2006) diffused more freely in the synaptic membrane (Fig. 5B). To quantitatively compare the diffusion behavior of a range of high- and low-affinity $\beta$-loop variants, we calculated the membrane areas explored by TMD- $\beta$ L-wt, TMD- $\beta$ L-HI, TMD- $\beta$ L-D407P/ F408G, TMD- $\beta$ L-geph-, as well as the construct TMD- $\beta$ L$\Delta$ Core in which the core binding domain was deleted (Fig. $5 C, D$; Table 4). For each trajectory, the area of the convex hull around the detections (normalized by the number of detections) was used as a measure of mobility (Renner et al., 2017). As an alternative approach, we derived the $D_{\text {eff }}$ from the mean squared displacement (MSD) plotted against time (Fig. $5 E, F$; Table 4). The average number of synapses was not significantly different between the five constructs (Table 5, $p>0.05)^{j}$. However, their diffusion properties at synapses differed strongly. Explored areas and $D_{\text {eff }}$ of TMD- $\beta L-\Delta$ Core at synapses were substantially larger than those of TMD- $\beta$ L-wt, but smaller than those of TMD- $\beta$ L-geph ${ }^{-}$(Fig. $5 C, E$, areas $p<0.001, D_{\text {eff }} p<$ $0.001)^{\mathrm{k}}$, confirming the presence of gephyrin-binding sequences besides the core binding pocket (Fig. 3). Similarly, the synaptic diffusion parameters of the low-affinity interactor TMD- $\beta$ L-D407P/F408G were larger than those of TMD- $\beta$ L-wt and TMD- $\beta$ L-HI (Fig. $5 C, E$, areas $p<$ $\left.0.001, \mathrm{D}_{\text {eff }} p<0.001\right)^{\prime}$. This observation is in line with the biochemical data and demonstrates that the perturbation (TMD- $\beta$ L-D407P/F408G) of the high-affinity interaction reduces the confinement of the membrane construct at synapses. Nonetheless, the TMD- $\beta$ L-D407P/F408G retains a low affinity for gephyrin, as shown by the fact that its mobility was below that of the binding-deficient construct TMD- $\beta$ L-geph ${ }^{-}\left(\text {areas } p<0.001, \mathrm{D}_{\text {eff }} p<0.001\right)^{\mathrm{m}}$. Conversely, the absence of the low-affinity site in TMD$\beta \mathrm{L}-\mathrm{HI}$ caused a significant acceleration compared to the wild-type $\left(D_{\text {eff }} p<0.001\right)^{n}$. These data show that lowaffinity interactions participate in the slowdown of $\beta$-loop constructs at synaptic gephyrin clusters. We observed similar changes in the mobility of all the variants outside of synapses (Fig. $5 D, F$; comparison of all areas $p<0.001$ and $\left.\mathrm{D}_{\text {eff }} p<0.001\right)^{\circ}$, indicating that binding processes between the $\beta$-loop and gephyrin also occur in the extrasynaptic area (Ehrensperger et al., 2007). Next, we inves- 
A

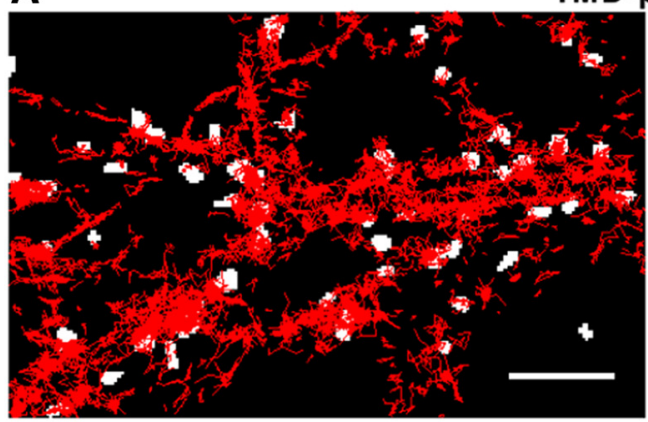

TMD- $\beta$ L-WT

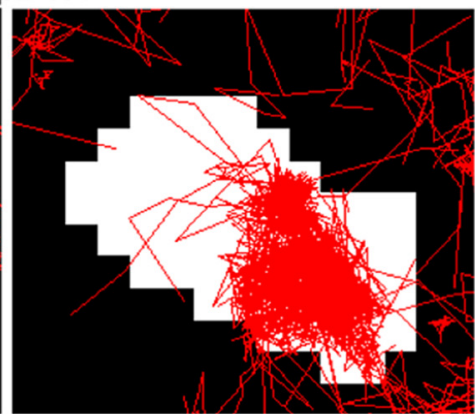

B

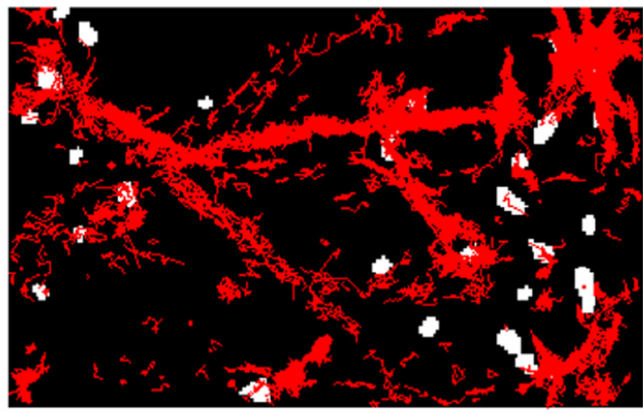

TMD- $\beta$ L-geph-

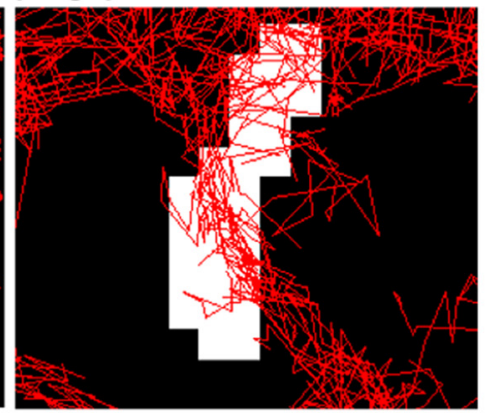

E

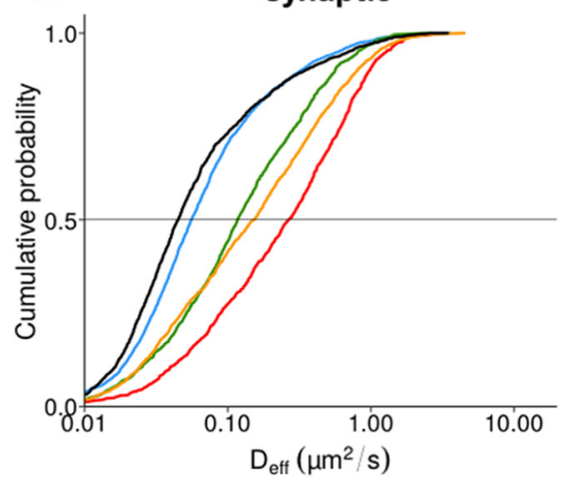

F

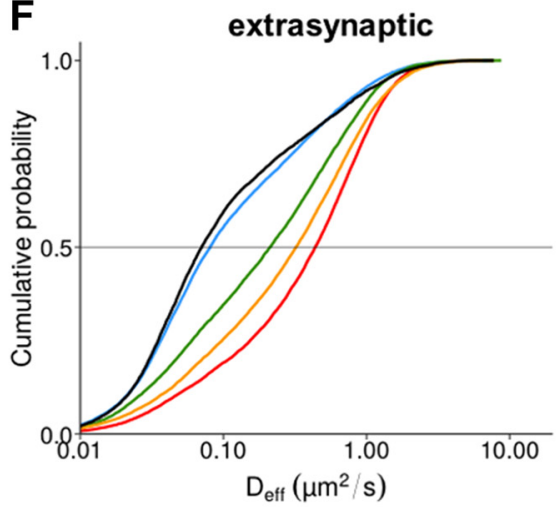

C

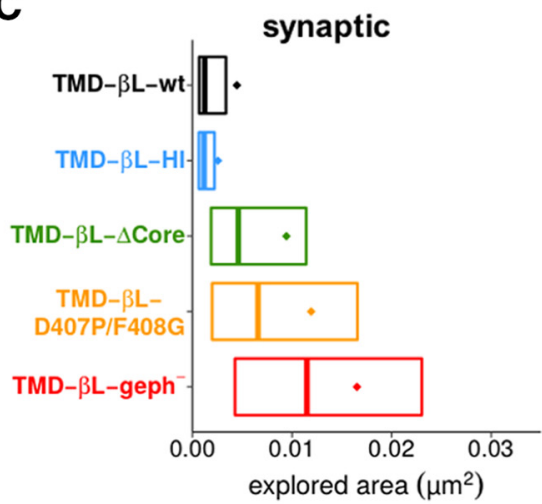

D

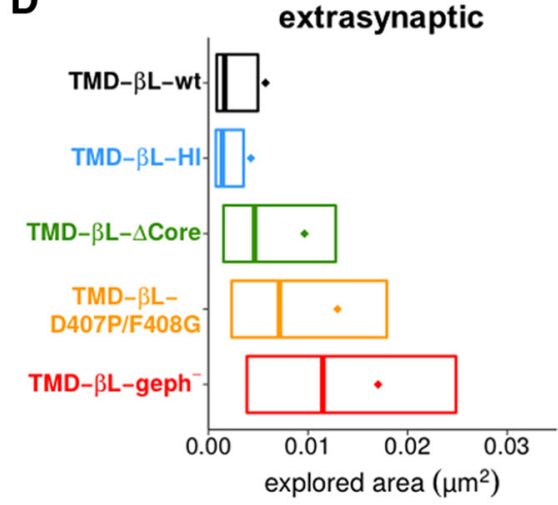

Figure 5. Membrane diffusion of TMD- $\beta$ L variants in spinal cord neurons. $\boldsymbol{A}, \boldsymbol{B}$, sptPALM was done using Dendra2-tagged TMD- $\beta$ L variants in cultured neurons as described in Materials and Methods. Single molecule trajectories were recorded in 10,000 frames at an acquisition rate of $15 \mathrm{~ms}$ (red traces). Active synapses were identified using FM 4-64 labeling (binarized fluorescence images shown in white). Left, High-density sptPALM of dendritic segments expressing TMD- $\beta$ L-WT (A) or the gephyrin binding-deficient construct TMD- $\beta$ L-geph ${ }^{-}(\boldsymbol{B})$. Right, Zoomed recordings showing confinement of TMD- $\beta$ L-WT at synapses $(\boldsymbol{A})$ as opposed to the high mobility of TMD- $\beta$ L-geph ${ }^{-}(\boldsymbol{B})$. Scale bar: $5 \mu \mathrm{m}$ (left panels); pixel size of FM-labeled synapses: $160 \mathrm{~nm}$ (right panels). C, $\boldsymbol{D}$, Comparison of the areas explored by the TMD- $\beta$ L variants at synapses $(\boldsymbol{C})$ and in the extrasynaptic compartment $(\boldsymbol{D})$, represented by the mean value (colored dots), the median, $25 \%$ and $75 \%$ quartiles of the trajectories (boxes). Explored areas were normalized by the number of detections for each trajectory. Data were compared via one-way ANOVA (Kruskal-Wallis test) followed by a post hoc Dunn's multiple comparison test: all pairs were significantly different from one another with $p<0.001$. $\boldsymbol{E}, \boldsymbol{F}$, Cumulative histogram of diffusion coefficients of TMD- $\beta$ L variants in spinal cord neurons. Diffusion coefficients at synapses vary according to the strength of $\beta$ L-gephyrin binding $(\boldsymbol{E})$. The variants display comparable diffusion behaviors at extrasynaptic locations $(\boldsymbol{F})$. Data were compared with one-way ANOVA (Kruskal-Wallis test) followed by a post hoc Dunn's multiple comparison test: for all pairs, $\mathrm{D}_{\text {eff }}$ was significantly different with $p<0.001$, except for TMD- $\beta$ L- $\Delta$ Core versus TMD- $\beta$ L-D407P/F408G at synapses with $p>0.05$ (median values and quartiles with statistical comparison are given in Tables 1,4). 
Table 4. Diffusion analysis of synaptic and extrasynaptic TMD- $\beta$ L variants and full-length GlyR $\beta$ subunits in rat spinal cord neurons

\begin{tabular}{|c|c|c|c|}
\hline & & Synaptic $^{8}$ & Extrasynaptic $^{9}$ \\
\hline Parameter & $\beta$-Loop variant & Q1/Q2/Q3 & Q1/Q2/Q3 \\
\hline \multirow{3}{*}{ Explored area $\left[10^{-3} \mu \mathrm{m}^{2}\right]^{1}$} & TMD- $\beta \mathrm{L}-\mathrm{HI}{ }^{4}$ & $0.64 / 1.16 / 2.21$ & $0.75 / 1.39 / 3.53$ \\
\hline & TMD- $\beta$ L-D407P/F408G ${ }^{6}$ & $1.97 / 6.58 / 16.56$ & $2.33 / 7.13 / 17.92$ \\
\hline & TMD- $\beta$ L-geph ${ }^{-7}$ & $4.27 / 11.50 / 23.03$ & $3.86 / 11.49 / 24.85$ \\
\hline \multirow{4}{*}{$D_{\text {eff }}\left[\mu m^{2} * s^{-1}\right]^{2}$} & TMD- $\beta$ L-wt ${ }^{3}$ & $0.02 / 0.05 / 0.11$ & $0.04 / 0.07 / 0.26$ \\
\hline & TMD- $\beta$ L-D407P/F408G ${ }^{6}$ & $0.05 / 0.15 / 0.40$ & $0.10 / 0.32 / 0.73$ \\
\hline & TMD- $\beta$ L-geph ${ }^{-7}$ & $0.09 / 0.27 / 0.62$ & $0.15 / 0.44 / 0.86$ \\
\hline & & Synaptic (thresholded) ${ }^{8}$ & Extrasynaptic (thresholded) ${ }^{9}$ \\
\hline Parameter & GlyR $\beta$ variant & Q1/Q2/Q3 & Q1/Q2/Q3 \\
\hline \multirow[t]{2}{*}{ Explored area $\left[10^{-3} \mu \mathrm{m}^{2}\right]^{1}$} & GlyR $\beta-w t^{10}$ & $0.54 / 0.73 / 1.05$ & $0.60 / 0.91 / 1.76$ \\
\hline & GlyR $\beta-\mathrm{HI}^{11}$ & $0.55 / 0.77 / 1.18$ & $0.63 / 0.96 / 1.88$ \\
\hline \multirow{3}{*}{$D_{\text {eff }}\left[\mu m^{2} * s^{-1}\right]^{2}$} & 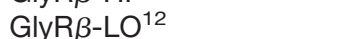 & $0.03 / 0.04 / 0.09$ & $0.04 / 0.09 / 0.19$ \\
\hline & GlyR $\beta-D 407 P / F 408 G^{13}$ & $0.03 / 0.04 / 0.09$ & $0.04 / 0.09 / 0.20$ \\
\hline & GlyR $\beta$-geph $^{-14}$ & $0.04 / 0.09 / 0.19$ & $0.05 / 0.11 / 0.22$ \\
\hline
\end{tabular}

Median values (Q2), 25\% (Q1), and 75\% (Q3) quartiles of the explored trajectory areas and $\mathrm{D}_{\text {eff }}$ from $>700$ synaptic trajectories and $>7000$ extrasynaptic trajectories for each construct. ${ }^{1}$ Explored area (in $10^{-3} \mu \mathrm{m}^{2}$ ); ${ }^{2} \mathrm{D}_{\text {eff }}$ (in $\mu \mathrm{m}^{2} / \mathrm{s}$ ); ${ }^{3}$ GlyR $\beta$-loop (residues $334-455$ ) C-terminally fused to TMD and Dendra2; ${ }^{4}$ GlyR $\beta$-loop with deletion $\Delta 378-393 ;{ }^{5}$ GlyR $\beta$-loop with deletion $\Delta 397-410 ;{ }^{6}$ GlyR $\beta$-loop with substitution D407P and F408G; ${ }^{7}$ GlyR $\beta$-loop with substitution F398A and I400A; 8 values for synaptic trajectories; ${ }^{9}$ values for extrasynaptic trajectories; 10 mEos $4 \mathrm{~b}$-tagged full-length human GlyR $\beta$ subunit; ${ }^{11}$ fulllength GlyR $\beta$ with deletion $\Delta 378-393 ;{ }^{12}$ full-length GlyR $\beta$ with deletion $\Delta 414-426$ ]; ${ }^{13}$ full-length GlyR $\beta$ with substitution D407P and F408G; ${ }^{14}$ full-length GlyR $\beta$ with substitution F398A and I400A. For the full-length GlyR $\beta$ variants, a threshold of $0.02 \mu \mathrm{m}^{2} / \mathrm{s}$ was applied (corresponding to the median $\mathrm{D}_{\text {eff }}$ of GlyR $\beta$-wt in fixed samples). The given Q1, Q2 and Q3 values only represent the trajectories above this threshold.

tigated possible contributions of the low- and high-affinity gephyrin binding sites of the $\beta$-loop on the synaptic and extrasynaptic mobilities of functional GlyRs.

\section{Diffusion behavior of high- and low-affinity variants of full-length GlyR complexes}

Full-length GlyRs are pentameric complexes composed of $\alpha$ and $\beta$ subunits. Recent quantitative PALM analyses of heteromeric GlyRs point to an $\alpha_{3}: \beta_{2}$ stoichiometry in spinal cord neurons (Patrizio et al., 2017). This means that two $\beta$-loops per GlyR complex can potentially interact with gephyrin, each interaction displaying either high or low affinity. to test the impact of the bimodal binding on the behavior of full-length GlyRs, we conducted sptPALM experiments with mEos $4 b$-tagged GlyR $\beta$ subunits in dissociated spinal cord cultures.

The median $D_{\text {eff }}$ and explored areas at synapses were similar for all constructs, with the exception of the binding-deficient variant GlyR $\beta$-geph ${ }^{-}$that displayed a much higher mobility (Fig. 6A). However, the synaptic diffusion coefficients of the binding-competent constructs were only marginally higher than the apparent diffusion of mEos $4 b-G l y R \beta$-wt in fixed samples (Fig. 6A, dotted line represents the median $D_{\text {eff }}$ ). On the one hand this is the result of the generally very low mobility of full-length receptor complexes at synapses due to molecular crowding (Renner et al., 2012). On the other hand, these results also show that both the low- and high-affinity sites individually contribute to a significant confinement of GlyRs at synaptic sites. To better resolve the differences in mobility, we have set a threshold for synaptic trajectories using the median $D_{\text {eff }}$ of GlyR $\beta$-wt in fixed samples $\left(0.02 \mu \mathrm{m}^{2} / \mathrm{s}\right)$, which constitutes the lower detection limit of our diffusion measurements (Fig. 6B). Under these conditions, the $D_{\text {eff }}$ as well as the explored areas of the synaptic trajectories above the threshold were significantly larger for GlyR $\beta-\mathrm{HI}$,

Table 5. Quantification of synapses per analyzed region in sptPALM recordings of TMD- $\beta$ L variants in rat spinal cord neurons

\begin{tabular}{|c|c|c|c|c|}
\hline$\overline{\beta \text {-Loop variant }}$ & Experiment $1^{1}$ & Experiment $2^{1}$ & Experiment $3^{1}$ & Average $^{2}$ \\
\hline TMD- $\beta$ L-wt ${ }^{3}$ & $53 \pm 15$ & $48 \pm 28$ & $53 \pm 0$ & $52 \pm 15$ \\
\hline TMD- $\beta \mathrm{L}-\mathrm{HI}^{4}$ & $66 \pm 39$ & $45 \pm 16$ & $100 \pm 23$ & $64 \pm 31$ \\
\hline TMD- $\beta$ L- $\Delta$ Core $^{5}$ & $64 \pm 20$ & $32 \pm 1$ & $85 \pm 91$ & $61 \pm 45$ \\
\hline TMD- $\beta$ L-D407P/F408G 6 & $37 \pm 4$ & $68 \pm 6$ & $48 \pm 12$ & $50 \pm 15$ \\
\hline TMD- $\beta$ L-geph -7 & $55 \pm 13$ & $107 \pm 35$ & $35 \pm 8$ & $72 \pm 40$ \\
\hline
\end{tabular}

Average number of synapses per experiment and for all experiments. ${ }^{1}$ Mean number of synapses per analyzed region and SD for the stated experiment (1, 2, or 3 ); 2 mean \pm SD of synapses for all three experiments; ${ }^{3}$ GlyR $\beta$-loop (residues $\left.334-455\right)$ C-terminally fused to TMD and Dendra2; ${ }^{4}$ GlyR $\beta$-loop with deletion $\Delta 378-$ 393; ${ }^{5}$ GlyR $\beta$-loop with deletion $\Delta 397-410 ;{ }^{6}$ GlyR $\beta$-loop with substitution D407P and F408G; ${ }^{7}$ GlyR $\beta$-loop with substitution F398A and I400A 
A

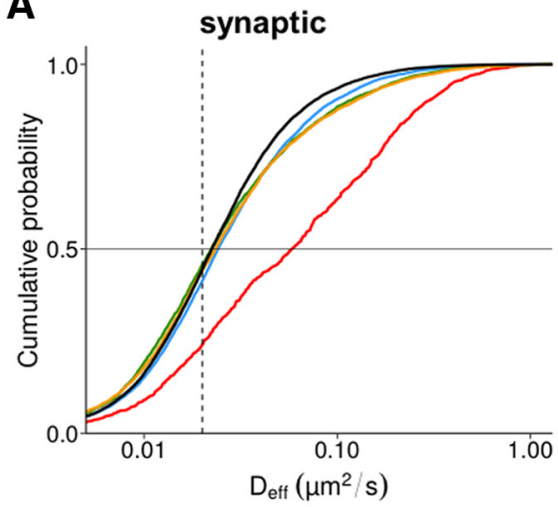

B

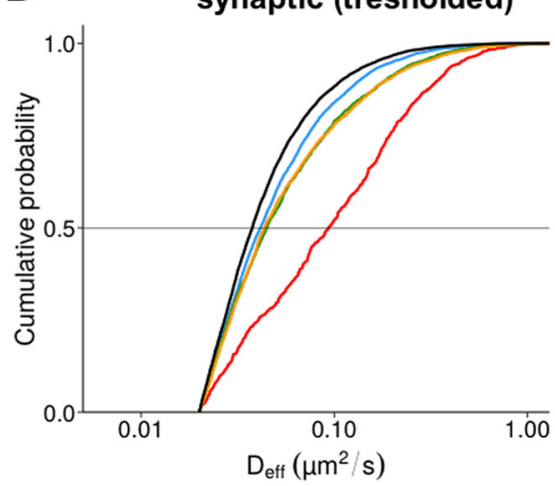

C

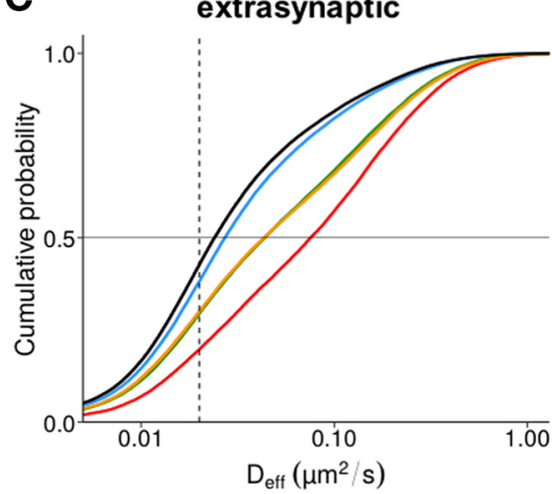

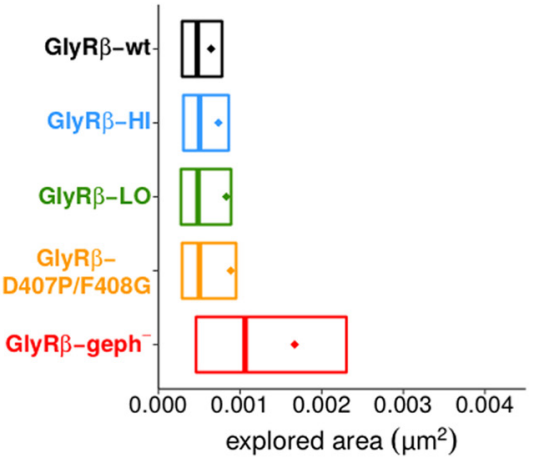
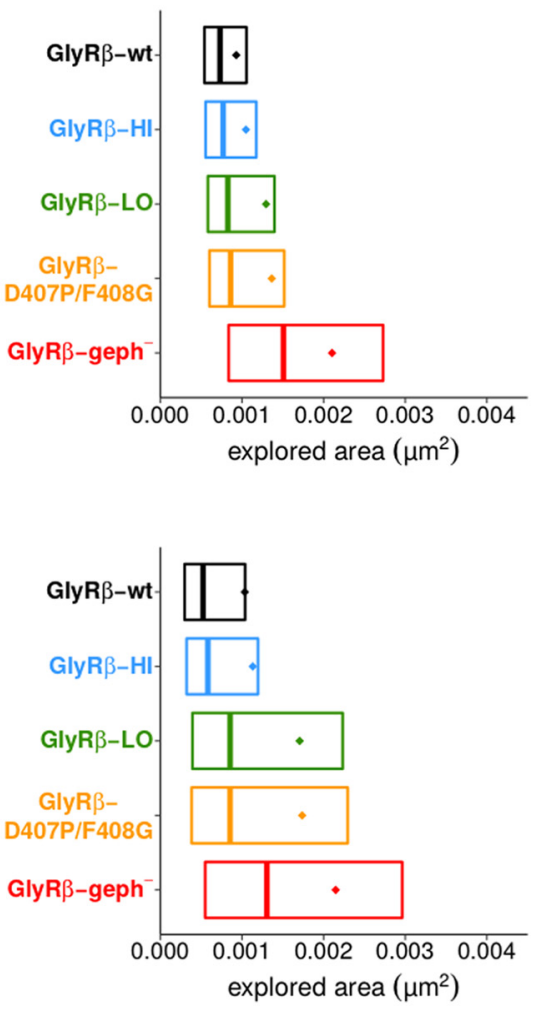

Figure 6. Single molecule diffusion of full-length GlyR complexes in spinal cord neurons. $\boldsymbol{A}, \mathrm{D}_{\text {eff }}$ (left panel) of mEos4b-tagged GlyRs at synapses were determined by sptPALM, using wild-type GlyR $\beta$ subunits (black trace) and the variants GlyR $\beta$-HI (blue), GlyR $\beta$-LO (green), GlyR $\beta$-D407P/F408G (yellow), and GlyR $\beta$-geph- (red). The dotted line indicates the median $\mathrm{D}_{\text {eff }}$ value of mEos4b-GlyR $\beta$-wt trajectories in a fixed sample $\left(0.02 \mu \mathrm{m}^{2} / \mathrm{s}\right)$ that is the limit of resolution in our recordings. The explored areas (normalized by the number of detections, right panel) are represented by their mean (colored dots), median, $25 \%$ and $75 \%$ quartiles (boxes) of the trajectory population. $\boldsymbol{B}$, Distribution of synaptic trajectories (data shown in $\boldsymbol{A}$ ) with $D_{\text {eff }}$ values $>0.02 \mu \mathrm{m}^{2} / \mathrm{s}$. Differences in the diffusion coefficients (left) and the corresponding areas (right) of the GlyR $\beta$ variants are evident for the thresholded data. Data were compared with one-way ANOVA (Kruskal-Wallis test) followed by a post hoc Dunn's multiple comparison test: explored areas and $\mathrm{D}_{\text {eff }}$ values were significantly different for all pairs $(p<0.0001$ ), except for GlyR $\beta$-LO versus GlyR $\beta$-D407P/F408G with $p>0.05$ (median values and quartiles are given in Table 4). $C$, $D_{\text {eff }}$ (left panel) and explored areas (right) of GlyR $\beta$ variants outside of synapses (significantly different between all conditions, $p<0.001$.

GlyR $\beta$-LO and GlyR $\beta$-D407P/F408G variants than those of the wild-type $\left(D_{\text {eff }} p<0.0001 \text {, areas } p<0.0001\right)^{\mathrm{p}}$, indicating that both binding modes play a role in the immobilization of GlyR complexes at synaptic gephyrin clusters. What is more, the relatively small difference between GlyR $\beta-\mathrm{HI}$ on the one hand, and GlyR $\beta$-LO or GlyR $\beta$-D407P/F408G on the other hand (Table 4), implies that the contribution of the low-affinity interaction may be more important than the binding studies would suggest. However, the presence of endogenous, wild-type GlyR $\beta$ subunits and the formation of mixed wild-type and mutant heteromeric complexes in infected neurons may produce intermediate effects that complicate the interpretation of these results. Outside of synapses, the pattern of GlyR $\beta$ 
mobility of the various constructs (Fig. $6 C$ ) closely matched that of the simple TMD- $\beta$ L constructs (Fig. $5 D, F$ ), confirming that the interaction between GlyRs and gephyrin also takes place at extrasynaptic membrane compartments. In addition, the data also suggest that extrasynaptic gephyrinGlyR interactions largely depend on the high-affinity site, while synaptic interactions have significant contributions of both, the low- and high-affinity site. Taken together, our sptPALM data recapitulate the ITC binding of GlyR $\beta$-loop variants, demonstrating that the interaction of GlyR $\beta$ and gephyrin is shaped by alternative modes of binding both in vitro as well as in living neurons.

\section{Discussion}

The efficiency of glycinergic signal transmission depends on the ability of gephyrin to immobilize GlyRs at synapses. The high-affinity interaction between gephyrin and the GlyR $\beta$-loop has been reported more than a decade ago (Schrader et al., 2004; Sola et al., 2004). However, the mode of interaction was found to be complex, comprising high- and low-affinity binding sites with unknown functional properties on the cellular level. Using a combination of molecular interaction studies and highdensity single-particle tracking, we have elucidated the underlying molecular determinants responsible for highand low-affinity interaction between GlyR and gephyrin and validated their contribution to the diffusion-trapping of the receptor at synapses in living cells.

The bimodal binding between gephyrin and GlyR relies on a sequence of 49 residues (378-426) in the GlyR $\beta$-loop (Schrader et al., 2004; Herweg and Schwarz, 2012). Within these 49 residues, a core binding sequence spanning residues 394-411 was shown to be critical for this interaction (Meyer et al., 1995), as confirmed by structural analysis (residues 398-410; Kim et al., 2006). Here we discovered that the core region in itself does not promote bimodal binding, but requires $\mathrm{N}$ - and $\mathrm{C}$-terminal flanking sequences to promote low- and high-affinity binding to full-length gephyrin, respectively. During interaction, an extended binding pocket on gephyrin is occupied by the $\mathrm{N}$-terminal low-affinity binding sequence of the $\beta$-loop. We concluded that the formation of the GlyR-gephyrin complex depends on additional binding sites within the E-domain as well as the C-domain of gephyrin that extend beyond the binding cleft identified in previous studies (Kim et al., 2006). Partial proteolysis of full-length gephyrin by trypsin (Herweg and Schwarz, 2012) in the presence of the $\beta$-loop provides further support to the concept that the $\beta$-loop makes contact with the $\mathrm{C}$-domain of gephyrin.

The functional relevance of our findings is supported by a recent study focusing on the involvement of gephyrin in a case of Dravet syndrome (Dejanovic et al., 2015). Genetic screening identified a mutation in the gephyrin E-domain that impairs inhibitory neurotransmission (Dejanovic et al., 2015). The affected residue (G375D) is located within the extended binding pocket of the $\mathrm{E}$-domain that is adjacent to the low-affinity interaction sequence of the GlyR $\beta$-loop. The reduced affinity of the $\beta$-loop for G375D gephyrin shows that mutations in the newly discovered low-affinity binding site can have direct consequences for inhibitory synaptic function.

Our data also provide evidence that high-affinity binding to gephyrin depends on the conformation of the C-terminal sequence flanking the core region of the GlyR $\beta$-loop. Despite numerous studies on the structure of the ECD or TM-domains of different LGICs (Corringer et al., 2012; Miller and Aricescu, 2014; Sauguet et al., 2014; Du et al., 2015; Huang et al., 2015), structural data of the intracellular domains (ICDs) of these receptors are largely lacking. Structural data from 5-HT3-receptor and nAchR suggest the presence of a helical structure (Unwin and Fujiyoshi, 2012; Hassaine et al., 2014) that appears to be conserved in the GlyR $\beta$-loop. We observed that the high-affinity interaction and bimodal binding of the $\beta$-loop with gephyrin is dependent on the presence of a $3_{10}$-helix beginning with residue 406 . Truncation of the GlyR $\beta$-loop at position 411 results in a disordered $C$ terminus (Maric et al., 2014b), supporting the notion that these residues contribute to the conformational integrity of the full-length interaction domain of the $\beta$-loop. Alternatively, replacing two critical residues of the $3_{10}$-helix also abolishes highaffinity binding. We therefore argue that the C-terminal flanking sequence adopts a conformation that involves the formation of a $3_{10}$-helix and enables the high-affinity interaction of the core-motif with gephyrin. A structural role of the ICDs has also been described in the context of the modulation of $\alpha 1$-subunit containing GlyRs by ethanol, G protein and interleukin-1 $\beta$ (Burgos et al., 2015; Patrizio et al., 2017). Given the significance of the $\beta$-loop conformation for high-affinity and bimodal binding, we thus propose to refer to this functional unit as ICD, rather than unstructured loop.

The consequences of the bimodal interaction between the $\beta-I C D$ and gephyrin on the diffusion-trapping of GlyRs at synapses was assessed using single-molecule imaging in living spinal cord neurons. Making use of a TMD- $\beta$ L construct that recapitulates the properties of full-length receptors in terms of cellular mobility and synaptic clustering (Specht et al., 2011; Specht et al., 2013; Masson et al., 2014), we were able to show a direct effect of highand low-affinity interactions on the mobility of the membrane proteins. Furthermore, the relative variations of the dynamics of the GlyR $\beta$ and TMD- $\beta$ L variants at synapses paralleled those in the extrasynaptic compartment, where a high proportion of GlyRs are known to be associated with gephyrin (Ehrensperger et al., 2007; Patrizio et al., 2017). We found that the binding affinities extracted from biochemical data correlate with the $D_{\text {eff }}$ at synapses determined by sptPALM (Fig. 7). Importantly, the findings with the TMD- $\beta$ L variants were reinforced by diffusion studies of full-length GlyRs containing tagged $\beta$-subunits, providing additional insight into the selective contribution of the low- and high-affinity gephyrin binding sites on synaptic and extrasynaptic receptor mobility.

According to our data, the major contribution to GlyR confinement can be assigned to the high-affinity site at both synaptic and extrasynaptic sites, with the low-affinity binding site mainly contributing to synaptic confinement. The functional relevance of the low-affinity site is evident 


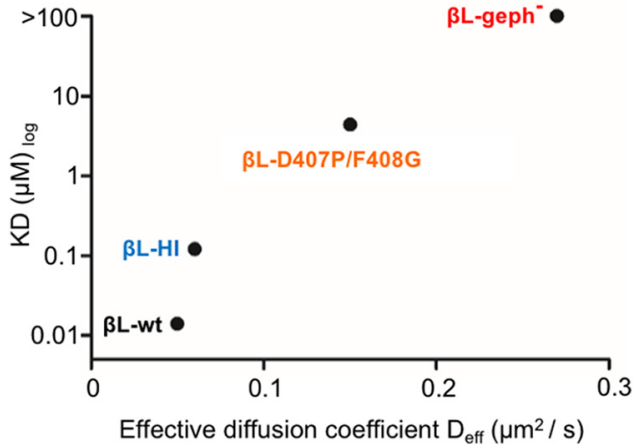

Figure 7. Correlation of in vitro binding affinities and diffusion coefficients. The binding affinities of $\beta \mathrm{L}-\mathrm{WT}$ (high-affinity site), $\beta \mathrm{L}-\mathrm{HI}$ and $\beta \mathrm{L}-\mathrm{D} 407 \mathrm{P} / \mathrm{F} 408 \mathrm{G}$ determined by ITC correlate with their $D_{\text {eff }}$ obtained by sptPALM recordings in living spinal cord neurons (TMD- $\beta$ L variants)

in the sptPALM recordings of full-length GlyRs, where the mobility of GlyR $\beta$-LO or GlyR $\beta$-D407P/F408G at synapses was only slightly greater than that of the GlyR $\beta-\mathrm{HI}$ variant. The low-affinity binding sites could either ensure a degree of flexibility of receptor clustering, or increase the occupancy of gephyrin clusters, or function in the finetuning of synaptic clusters. This may contribute to the dynamic equilibrium between synaptic and extrasynaptic receptors during synaptic plasticity (Specht et al., 2011) as well as the competition between GlyRs and $\mathrm{GABA}_{\mathrm{A}} \mathrm{Rs}$ (Maric et al., 2011). We believe that the identified interaction domains in GlyR $\beta$ are primarily important for the binding to gephyrin and not to other synaptic proteins or cytoskeletal elements. Disruption of gephyrin binding by the exchange of two critical hydrophobic amino acids in the binding pocket (Kim et al., 2006) resulted in a further acceleration of the diffusion, exceeding the mobility of the high- and low-affinity variants. Also, the dependence of GlyR-gephyrin binding on the $\beta$-subunit was demonstrated in a reduced cellular system in the absence of endogenous components (Patrizio et al., 2017).

Full-length gephyrin forms trimers and interacts in vitro with isolated $\beta$-loop peptides through high- and lowaffinity interactions, whereas isolated dimeric E-domains lack these properties. This is in contrast to an earlier study (Schrader et al., 2004), in which the binding of the E-domain was fitted with a two-site model. However, careful inspection of the data shows that in comparison to full-length gephyrin, the number of binding sites was $\sim 50 \%$ lower (Schrader et al., 2004). The results of our current study also show that only half of the binding sites in the GephE dimer are occupied, supporting the interpretation that E-domain dimerization and full receptor occupancy are mutually exclusive. Based on the trimerization and dimerization of the isolated gephyrin G- and E-domains (Schwarz et al., 2001; Sola et al., 2004; Kim et al., 2006) a hexagonal lattice beneath the postsynaptic membrane has been proposed as a clustering principle of gephyrin (Kneussel and Betz, 2000), although proof of this concept on the cellular or functional level is still missing. According to our results, a high receptor occupancy could only be reached if the E-domain dimerization within the gephyrin cluster is incomplete. Indeed, recent data have shown that the organization of gephyrin clusters is rather loose and irregular (Specht et al., 2013; Linsalata et al., 2014; Dzyubenko et al., 2016), therefore potentially providing numerous unoccupied binding sites (Patrizio et al., 2017).

Gephyrin clusters undergo a constant dynamic reorganization (Specht et al., 2013), which could allow for structural flexibility and heterogeneity of receptor binding sites within a given cluster. On average, $\sim 200-300$ gephyrin molecules are present at synapses in cultured spinal cord neurons, with a large variability between individual synapses (Specht et al., 2013; Patrizio et al., 2017). The proportion of unbound gephyrin within the synaptic cluster determines its capacity to trap receptors (Holcman and Triller, 2006). Given the existence of high- and lowaffinity interactions between gephyrin and GlyR $\beta$, the state of gephyrin oligomerization and prior receptor occupancy could have an important impact on the recruitment of additional GlyRs at synapses. More specifically, the $\mathrm{C}$-terminal flanking sequence of the $\beta$-ICD can only confer high-affinity binding to unbound gephyrin, suggesting that it plays a role in the formation of extrasynaptic GlyR-gephyrin nano-complexes that can then be added to an existing synaptic cluster. In contrast, lowaffinity interactions involving the $\mathrm{N}$-terminal sequences of the $\beta$-ICD can potentially occupy every free binding site. Low-affinity interactions may therefore cause a transient immobilization of unbound GlyR complexes by the synaptic gephyrin scaffold that could lead to their subsequent stabilization.

In conclusion, we have combined two different approaches to explore the binding properties of synaptic components, biochemical interaction studies using microcalorimetry and high-resolution diffusion analysis using sptPALM. Our strategy thus bridges the gap between thermodynamic binding processes analyzed in vitro and the diffusion-trapping of receptors in living neurons. The correlation between binding affinities and diffusion parameters implies that molecular interactions can be derived from single molecule tracking data, setting the stage for an emerging field of chemistry in cellulo.

\section{References}

Belaidi AA, Schwarz G (2013) Metal insertion into the molybdenum cofactor: product-substrate channelling demonstrates the functional origin of domain fusion in gephyrin. Biochem J 450:149-157. CrossRef

Biron Z, Khare S, Samson AO, Hayek Y, Naider F, Anglister J (2002) A monomeric 3(10)-helix is formed in water by a 13-residue peptide representing the neutralizing determinant of HIV-1 on gp41. Biochemistry 41:12687-12696. CrossRef

Burgos CF, Castro PA, Mariqueo T, Bunster M, Guzmán L, Aguayo LG (2015) Evidence for $\alpha$-helices in the large intracellular domain mediating modulation of the $\alpha 1$-glycine receptor by ethanol and G $\beta \gamma$. J Pharmacol Exp Ther 352:148-155. CrossRef

Choquet D, Triller A (2003) The role of receptor diffusion in the organization of the postsynaptic membrane. Nat Rev Neurosci 4:251-265. CrossRef Medline

Choquet D, Triller A (2013) The dynamic synapse. Neuron 80:691703. CrossRef Medline 
Corringer PJ, Poitevin F, Prevost MS, Sauguet L, Delarue M, Changeux JP (2012) Structure and pharmacology of pentameric receptor channels: from bacteria to brain. Structure 20:941-956. CrossRef

Dahan M, Levi S, Luccardini C, Rostaing P, Riveau B, Triller A (2003) Diffusion dynamics of glycine receptors revealed by singlequantum dot tracking. Science 302:442-445. CrossRef

de Chaumont F, Dallongeville S, Chenouard N, Hervé N, Pop S, Provoost T, Meas-Yedid V, Pankajakshan P, Lecomte T, Le Montagner Y, Lagache T, Dufour A, Olivo-Marin JC (2012) Icy: an open bioimage informatics platform for extended reproducible research. Nat Methods 9:690-696. CrossRef

Dejanovic B, Djémié T, Grünewald N, Suls A, Kress V, Hetsch F, Craiu D, Zemel M, Gormley P, Lal D; EuroEPINOMICS Dravet working group, Myers CT, Mefford HC, Palotie A, Helbig I, Meier JC, De Jonghe P, Weckhuysen S, Schwarz G (2015) Simultaneous impairment of neuronal and metabolic function of mutated gephyrin in a patient with epileptic encephalopathy. EMBO Mol Med 7:1580-1594. CrossRef

Du J, Lü W, Wu S, Cheng Y, Gouaux E (2015) Glycine receptor mechanism elucidated by electron cryo-microscopy. Nature 526: 224-229. CrossRef

Dzyubenko E, Rozenberg A, Hermann DM, Faissner A (2016) Colocalization of synapse marker proteins evaluated by STEDmicroscopy reveals patterns of neuronal synapse distribution in vitro. J Neurosci Methods 273:149-159. CrossRef

Ehrensperger MV, Hanus C, Vannier C, Triller A, Dahan M (2007) Multiple association states between glycine receptors and gephyrin identified by SPT analysis. Biophys J 92:3706-3718. CrossRef

Fritschy JM, Harvey RJ, Schwarz G (2008) Gephyrin: where do we stand, where do we go? Trends Neurosci 31:257-264. CrossRef

Hassaine G, Deluz C, Grasso L, Wyss R, Tol MB, Hovius R, Graff A, Stahlberg H, Tomizaki T, Desmyter A, Moreau C, Li XD, Poitevin F, Vogel H, Nury H (2014) X-ray structure of the mouse serotonin 5-HT3 receptor. Nature 512:276-281. CrossRef

Havarushka N, Fischer-Schrader K, Lamkemeyer T, Schwarz G (2014) Structural basis of thermal stability of the tungsten cofactor synthesis protein MoaB from Pyrococcus furiosus. PLoS One 9:e86030. CrossRef

Herweg J, Schwarz G (2012) Splice-specific glycine receptor binding, folding, and phosphorylation of the scaffolding protein gephyrin. J Biol Chem 287:12645-12656. CrossRef

Holcman D, Triller A (2006) Modeling synaptic dynamics driven by receptor lateral diffusion. Biophys J 91:2405-2415. CrossRef

Huang X, Chen H, Michelsen K, Schneider S, Shaffer PL (2015) Crystal structure of human glycine receptor- $\alpha 3$ bound to antagonist strychnine. Nature 526:277-280. CrossRef

Karpen ME, de Haseth PL, Neet KE (1992) Differences in the amino acid distributions of 3(10)-helices and alpha-helices. Protein Sci 1:1333-1342. CrossRef

Kim EY, Schrader N, Smolinsky B, Bedet C, Vannier C, Schwarz G, Schindelin $\mathrm{H}$ (2006) Deciphering the structural framework of glycine receptor anchoring by gephyrin. EMBO J 25:1385-1395. CrossRef

Kirsch J, Wolters I, Triller A, Betz H (1993) Gephyrin antisense oligonucleotides prevent glycine receptor clustering in spinal neurons. Nature 366:745-748. CrossRef

Kneussel M, Betz H (2000) Clustering of inhibitory neurotransmitter receptors at developing postsynaptic sites: the membrane activation model. Trends Neurosci 23:429-435. CrossRef

Kneussel M, Hermann A, Kirsch J, Betz H (1999) Hydrophobic interactions mediate binding of the glycine receptor beta-subunit to gephyrin. J Neurochem 72:1323-1326. CrossRef

Kowalczyk S, Winkelmann A, Smolinsky B, Förstera B, Neundorf I, Schwarz G, Meier JC (2013) Direct binding of GABAA receptor $\beta 2$ and $\beta 3$ subunits to gephyrin. Eur J Neurosci 37:544-554. CrossRef

Levi S, Logan SM, Tovar KR, Craig AM (2004) Gephyrin is critical for glycine receptor clustering but not for the formation of functional GABAergic synapses in hippocampal neurons. J Neurosci 24:207217. CrossRef
Linsalata AE, Chen X, Winters CA, Reese TS (2014) Electron tomography on $\gamma$-aminobutyric acid-ergic synapses reveals a discontinuous postsynaptic network of filaments. J Comp Neur 522:921936. CrossRef

Lois C, Hong EJ, Pease S, Brown EJ, Baltimore D (2002) Germline transmission and tissue-specific expression of transgenes delivered by lentiviral vectors. Science 295:868-872. CrossRef

Manley S, Gillette JM, Patterson GH, Shroff H, Hess HF, Betzig E, Lippincott-Schwartz J (2008) High-density mapping of singlemolecule trajectories with photoactivated localization microscopy. Nat Methods 5:155-157. CrossRef

Maric HM, Mukherjee J, Tretter V, Moss SJ, Schindelin H (2011) Gephyrin-mediated $\gamma$-aminobutyric acid type A and glycine receptor clustering relies on a common binding site. J Biol Chem 286:42105-42114. CrossRef

Maric HM, Kasaragod VB, Hausrat TJ, Kneussel M, Tretter V, Strømgaard K, Schindelin H (2014a) Molecular basis of the alternative recruitment of $\mathrm{GABA}(\mathrm{A})$ versus glycine receptors through gephyrin. Nat Commun 5:5767.

Maric HM, Kasaragod VB, Schindelin H (2014b) Modulation of gephyrin-glycine receptor affinity by multivalency. ACS Chem Biol 9:2554-2562.

Masson JB, Dionne P, Salvatico C, Renner M, Specht CG, Triller A, Dahan M (2014) Mapping the energy and diffusion landscapes of membrane proteins at the cell surface using high-density singlemolecule imaging and Bayesian inference: application to the multiscale dynamics of glycine receptors in the neuronal membrane. Biophys J 106:74-83. CrossRef

Meyer G, Kirsch J, Betz H, Langosch D (1995) Identification of a gephyrin binding motif on the glycine receptor beta subunit. Neuron 15:563-572. Medline

Miller PS, Aricescu AR (2014) Crystal structure of a human GABAA receptor. Nature 512:270-275.

Patrizio A, Renner M, Pizzarelli R, Triller A, Specht CG (2017) Alpha subunit-dependent glycine receptor clustering and regulation of synaptic receptor numbers. Sci Rep 7:10899. CrossRef

Petrini EM, Barberis A (2014) Diffusion dynamics of synaptic molecules during inhibitory postsynaptic plasticity. Front Cell Neurosci 8:300. CrossRef

Racine V, Sachse M, Salamero J, Fraisier V, Trubuil A, Sibarita JB (2007) Visualization and quantification of vesicle trafficking on a three-dimensional cytoskeleton network in living cells. J Microsc 225:214-228. CrossRef

Renner M, Schweizer C, Bannai H, Triller A, Lévi S (2012) Diffusion barriers constrain receptors at synapses. PLoS One 7:e43032. CrossRef

Renner M, Wang L, Levi S, Hennekinne L, Triller A (2017) A simple and powerful analysis of lateral subdiffusion using single particle tracking. Biophys J 113:2452-2463. CrossRef

Sander B, Tria G, Shkumatov AV, Kim EY, Grossmann JG, Tessmer I, Svergun DI, Schindelin H (2013) Structural characterization of gephyrin by AFM and SAXS reveals a mixture of compact and extended states. Acta Crystallogr D Biol Crystallogr 69:20502060. CrossRef

Sauguet L, Shahsavar A, Poitevin F, Huon C, Menny A, Nemecz À, Haouz A, Changeux JP, Corringer PJ, Delarue M (2014) Crystal structures of a pentameric ligand-gated ion channel provide a mechanism for activation. Proc Natl Acad Sci USA 111:966-971. CrossRef

Schrader N, Kim EY, Winking J, Paulukat J, Schindelin H, Schwarz G (2004) Biochemical characterization of the high affinity binding between the glycine receptor and gephyrin. J Biol Chem 279: 18733-18741. CrossRef

Schwarz G, Schrader N, Mendel RR, Hecht HJ, Schindelin H (2001) Crystal structures of human gephyrin and plant $\mathrm{Cnx} 1 \mathrm{G}$ domains: comparative analysis and functional implications. J Mol Biol 312: 405-418. CrossRef

Sergé A, Bertaux N, Rigneault H, Marguet D (2008) Dynamic multiple-target tracing to probe spatiotemporal cartography of cell membranes. Nat Methods 5:687-694. CrossRef 
Sola M, Bavro VN, Timmins J, Franz T, Ricard-Blum S, Schoehn G, Ruigrok RW, Paarmann I, Saiyed T, O'Sullivan GA, Schmitt B, Betz $H$, Weissenhorn W (2004) Structural basis of dynamic glycine receptor clustering by gephyrin. EMBO J 23:2510-2519. CrossRef Specht CG, Grünewald N, Pascual O, Rostgaard N, Schwarz G, Triller A (2011) Regulation of glycine receptor diffusion properties and gephyrin interactions by protein kinase C. EMBO J 30:38423853. CrossRef

Specht CG, Izeddin I, Rodriguez PC, El Beheiry M, Rostaing P, Darzacq X, Dahan M, Triller A (2013) Quantitative nanoscopy of inhibitory synapses: counting gephyrin molecules and receptor binding sites. Neuron 79:308-321. CrossRef

Tretter V, Jacob TC, Mukherjee J, Fritschy JM, Pangalos MN, Moss SJ (2008) The clustering of GABA(A) receptor subtypes at inhibitory synapses is facilitated via the direct binding of receptor alpha 2 subunits to gephyrin. J Neurosci 28:1356-1365. CrossRef
Tretter V, Kerschner B, Milenkovic I, Ramsden SL, Ramerstorfer J, Saiepour L, Maric HM, Moss SJ, Schindelin H, Harvey RJ, Sieghart W, Harvey K (2011) Molecular basis of the $\gamma$-aminobutyric acid A receptor $\alpha 3$ subunit interaction with the clustering protein gephyrin. J Biol Chem 286:37702-37711. CrossRef

Tyagarajan SK, Fritschy JM (2014) Gephyrin: a master regulator of neuronal function? Nat Rev Neurosci 15:141-156. CrossRef Medline

Unwin N (2005) Refined structure of the nicotinic acetylcholine receptor at 4A resolution. J Mol Biol 346(4), pp. 967-989. Medline

Unwin N, Fujiyoshi Y (2012) Gating movement of acetylcholine receptor caught by plunge-freezing. J Mol Biol 422:617-634. CrossRef

Zacchi P, Dreosti E, Visintin M, Moretto-Zita M, Marchionni I, Cannistraci I, Kasap Z, Betz H, Cattaneo A, Cherubini E (2008) Gephyrin selective intrabodies as a new strategy for studying inhibitory receptor clustering. J Mol Neurosci 34:141-148. CrossRef 